\title{
Building E-commerce Satisfaction and Boosting Sales: the role of social commerce trust \\ and its antecedents
}

\begin{abstract}
Consumers are increasingly relying on social commerce for making their purchase decisions, and e-vendors have great interests in applying social commerce features in the traditional e-commerce sites to increase sales. Although the importance of trust has been well recognized in the literature, the previous studies have mainly focused on trust in e-commerce sites and failed to incorporate its multi-dimensional nature to study consumer behavior. To gain further insights into consumer decision-making, this study aims to develop a social commerce trust-based consumer decisionmaking framework. Based on the social-technical theory, we conceptualize social commerce trust in a multi-dimensional view including trust in social media, trust in e-commerce sites, trust in social commerce features and trust in consumers. Data was collected from an online survey taken by American Amazon consumers. Our results strongly support our new conceptualization of social commerce trust and demonstrate its importance by examining its effects on e-commerce outcomes. Further, trust in consumers and trust in social commerce features have stronger effects than trust in e-commerce sites and trust in social media in the formation of social commerce trust. Our study contributes to the theory by introducing the new conceptualization of social commerce trust and advancing our understanding of how to enhance social commerce trust. Practitioners can gain insights into the implementation of social commerce for building consumer trust and increasing sales.
\end{abstract}

Keywords: customer review quality, e-commerce satisfaction, purchasing behavior, social commerce trust, social support 


\section{Introduction}

As an emerging topic, social commerce recently has gained popularity in both research and practice. It refers to "any commercial activities facilitated by or conducted through the broad social media and Web 2.0 tools in consumers' online shopping processes or business' interactions with their customers” [65, p.191] $]^{1}$. It explores social media-enabled commercial activities and their business values, such as branding, consumer services, and firm performance (e.g., [59, 62, 65, 109, 111]). Social commerce has become a popular venue that offers a large amount of information about products and services contributed by both marketers and volunteer consumers. For example, more than 3 million seller feedback reviews are posted per month on Amazon.com [27].

Consumers are increasingly using social commerce as a source of product-related information and are participating in social media-enabled commercial activities such as customer review, sharing, recommendations, and discussions. For example, a recent report [34] shows that $45 \%$ of consumers interact with product reviews during the purchase process. Social commerce thus represents a new channel for consumers to acquire consumer-generated information, which is helpful for consumer product evaluations and purchasing decisions [35, 40, 77, 107]. Social commerce offers an effective approach for firms to deeply interact with their customers and build relationships, which is essential for firms to achieve a competitive advantage and improve their performance.

Research on social commerce has mainly focused on examining social commerce activities via social media $^{2}$ (e.g., [63, 74, 75, 108]). For example, Liang, Ho, Li, and Turban [63] find that social support and relationship quality play important roles in determining social commerce intention in a specific social commerce research context; that is, social media. Similarly, Zhang, Lu, Gupta, and Zhao

\footnotetext{
${ }^{1}$ In other words, social commerce includes buying and selling on social media or facilitated by social media tools. For example, consumers may see product information posted by their friends on Facebook, and decide to purchase the product later.

${ }^{2}$ Here social media platforms include general platforms such as Facebook and specific social shopping communities (e.g., [75]). These social shopping communities provide features such as recommendations, ratings, and consumer profiles. Consumers can make purchase by clicking links of participating e-commerce sites. Therefore, social shopping is a specific social media context of social commerce.
} 
[106] report that user participation and virtual experience have a significant influence on social commerce intention on social media. Another type of social commerce phenomenon integrates social media into traditional e-commerce. In this context, consumers can share their shopping-related information on social media through e-commerce sites. For example, Amazon integrates Facebook, Twitter, and Pinterest on its site. By clicking social media links for certain products, consumers can share product information on their Facebook page and write their opinions. Their friends can then see the posted information and visit product pages on Amazon by clicking the posts. To our knowledge, few studies have attempted to examine this type of social commerce (context of study in Appendix A), which motives us to investigate the effects of social commerce on e-commerce outcomes.

In the Information Systems (IS) discipline, trust has been largely studied to understand consumer behavior that leads to e-commerce outcomes $[4,6,30,55,72,80]$. Such studies have indicated that consumer trust is essential for e-vendors to drive consumer online transactions. Given that an ecommerce transaction may involve many components, such as companies, consumers, products, and web technology, consumer trust has been traditionally measured from a range of perspectives. Therefore, studies have argued that there is a need to measure consumer trust from a multi-dimensional perspective and examine its influences on online consumer behavior [30, 56, 71].

Social commerce can be viewed as a type of relational service market where trust plays an important role in determining the relationship quality between users and companies, and thus in generating business outcomes [63, 74, 108]. According to Zhang and Wang [110], social commerce consists of various facets including people, management, technology, and information. Similarly, other studies indicate that social commerce involves multiple features ${ }^{3}$ including social features, commercial features, and technological features [47, 48]. From this perspective, the multi-dimensional nature of

\footnotetext{
${ }^{3}$ Our study uses social commerce features to refer to those features integrated into e-commerce sites to fuel consumers' interaction with others, such as posting/responding to product reviews, rating reviews' helpfulness, and sharing products and their reviews through social media. These features are selected because they enable consumers to interact with each other and exchange product information.
} 
trust also applies to consumer trust in social commerce. However, prior trust studies have failed to take this into account, and have measured trust from a single-dimensional viewpoint primarily focusing on trust in sites (object of trust in Appendix A). In addition, understanding the nature and antecedents of consumer trust in social commerce would provide further insight into the social commerce phenomenon and its business outcomes. Therefore, our objective of this study is to conceptualize social commerce trust from a multi-dimensional perspective and identify its antecedents from a social commerce perspective.

To summarize, our review (see Appendix A) shows that trust in the literature has been examined separately mainly focusing on the object of sites and customers. To address this research gap, our study conceptualizes social commerce trust from a multi-dimensional perspective including e-commerce sites, customers, social media, and social commerce features. To the best of our knowledge, it is one of the first attempts to link between different perspectives of trust. We then develop a social commercebased trust consumer decision-making model that conceptualizes social commerce trust and examines its effects on e-commerce outcomes and its antecedents from a social commerce perspective. To that end, our work is set in a specific social commerce research context, integrating social commerce features into the traditional e-commerce setting. As such, our work makes contributions to the trust literature by conceptualizing the multi-dimensional social commerce trust and further clarifying the role of each dimension in forming consumers' social commerce trust, and thus providing a deeper understanding of social commerce trust. In addition, it expands the understanding of the emerging social commerce phenomenon and especially its role in building consumer trust and driving consumers' purchase behaviors. From the practical perspective, our work delivers insights for marketers into how to build consumer trust through the application of social commerce to increase sales.

The rest of the paper is organized as follows. First, we introduce social-technical theory, from which we conceptualize social commerce trust based on the literature on consumer trust and social commerce. Second, we develop our framework for a social commerce-based trust consumer decision-making 
model by integrating social commerce-based antecedents, social commerce trust, and e-commerce outcomes. Next, the research method and results are presented. Finally, the implications and limitations of our study, and opportunities for future research are discussed.

\section{Literature Review and Theoretical Background}

In this section, we first review previous literature on trust in the research context of consumer behavior/purchase and identify the gap in the literature. We then conceptualize social commerce trust based on social-technical theory.

\section{Literature Review on Trust}

Trust is defined as "the willingness of a party [the trustor] to be vulnerable to the actions of another party based on the expectation that the other [the trustee] will perform a particular action important to the trustor, irrespective of the ability to monitor or control that other party” [69, p.712]. Our study focuses on trust beliefs (i.e., a temporary state of trust) [71], which reflect consumers’ perceptions toward specific e-commerce sites. Ross and LaCroix [87] summarize that trust beliefs have three orientations: 1) trust derived from a cooperative motivational orientation, (2) trust caused by predictability, and (3) trust from a problem-solving. In the context of our study, predictable cooperative operations of e-commerce sites can help consumers establish their trust and support their purchase decisions. Therefore, Mayer, Davis, and Schoorman [69]'s definition of trust is chosen, which is consistent with the orientation that trust is caused by predictability. Following this definition, trust needs to be measured from a multi-dimensional perspective, including different trustees in social commerce.

Trust is an important concept in e-commerce and it can support important positive outcomes, such as purchase intention [7, 45], electronic word-of-mouth (WOM) [1], loyalty [15], and revisit intention [17]. Consumers can feel concerned to transact online due to various risks [72]. For example, Hong and Cha [45] find that consumers are less likely to purchase with a higher level of performance risk (i.e., low product quality), psychological risk (i.e., mental discomfort), financial risk (monetary loss), 
and payment risks (i.e., information misuse). Trust can create a comfortable environment so that individuals feel less concerned about the risks associated with e-commerce.

Previous literature has argued that trust in the context of e-commerce has several dimensions including system and interpersonal $[70]^{4}$. Our literature review (Appendix A) shows that previous literature has mainly focused on consumers' trust in sites, though some studies also recognize the importance of interpersonal trust and examine antecedents and outcomes of consumers' trust in consumers in the context of social media $[15,89,104]$. Further, as social media becomes increasingly popular, recent studies also assess the role of trust in social media which can positively increase consumers' purchase intentions [1, 15, 38]. Overall, previous studies have provided a rich understanding of how trust in different objects (e.g., sites, peers, social media) can affect consumer decision making, and thus generating positive e-commerce outcomes.

As social media has been integrated into traditional e-commerce sites ${ }^{5}$, the environment of ecommerce becomes more complex and there is a need to further understand consumers' trust in this emerging environment. Our review shows that there remain several limitations in previous literature. First, trust in social media has not gained much attention. Our review shows that those studies examining trust in social media has focused on the context of social media only and no studies have examined the role of trust in social media in the context of e-commerce sites. Such studies are highly needed because social media integrated into e-commerce sites can influence consumers’ trust toward e-commerce overall. For example, Amazon has integrated social media (i.e., Facebook, Twitter and Pinterest) into its site and consumers can post their assessments toward products on social media through Amazon. In such a scenario, trust in social media plays an important role, and consumers may

\footnotetext{
${ }^{4}$ McKnight and Chervany [70] also propose the third dimension of trust: intrapersonal, which refers to consumers' propensity to trust. Since our study does not focus on individuals' characteristics, intrapersonal dimension of trust is not included in our study. ${ }^{5}$ Here specific types of social media integrated into e-commerce may vary from site to site and depend on the information to share. For example, at the time of our study, Amazon integrates Facebook, Twitter, and Pinterest to share product description and pictures. In the future, it would be possible that other types of social media such as YouTube would be integrated into e-commerce sites to support product video sharing.
} 
not trust the overall environment of Amazon if they feel that their posted information on social media can be misused. Second, no studies have examined trust in social commerce features. In e-commerce sites such as Amazon, these new features empower consumers to (1) post reviews including their comments/feedbacks to certain products; (2) respond to other consumers' review; (3) rate the helpfulness of reviews; and (4) share product and their reviews through social media. In other words, the features offer the affordances that enable consumers to engage in the additional activities outlined above [61], and such affordances can help fuel interaction, and thus building consumers' trust. These features are vital to facilitate consumers' interactions and online purchase. Therefore, it is important to assess the role of consumers' trust in social commerce features. Third, previous literature has examined trust with various objects separately, but few studies have examined consumers' trust toward ecommerce. One exception is from Yoon and Occeña [104], who use “global” items to assess consumers' trust in mobile-commerce (m-commerce) (e.g., “C2C e-commerce is unreliable.”). However, according to MacKenzie [68], using "global” items may not be appropriate because these indicators can be ambiguous in their definition and construction of e-commerce trust, and there is no way to understand how participants come to their responses.

Unlike e-commerce, social commerce is a consumer-centered service market with a focus on interactions among consumers that integrates user-generated content into traditional e-commerce through the advantages offered by social media web technology [110]. From the technology perspective, social commerce has incorporated emerging technology objects (social media and social commerce features) into traditional e-commerce sites. Form the people perspective, consumers are the primary users that produce the user-generated content that serves as the foundation for social support and social relationships in social commerce. It is clear that social commerce has added new objects that can formulate consumer trust, and the extant literature on trust has failed to capture those new objects based on the above discussion. Thus, there is a need to refine trust in order to reflect the multiple-dimensional nature of social commerce. 
Based upon the discussion above, we identify different dimensions of social commerce trust including sites (e.g., e-vendors), social commerce features, social media, and consumers. The importance of trust in site has been emphasized in the literature since this is the target which consumers conduct transactions with (e.g., [57, 67]). Because e-commerce sites add social commerce features and integrate with social media to fuel social interaction to better cater consumers' specific needs, consumer trust in both social commerce features and social media can contribute to consumers' overall perception regarding whether the entire e-commerce environment is trustworthy $[41,88]$. Finally, trust in consumers is also vital because consumers interact with others via social commerce features and social media, and such a process can significantly influence their purchase process [104].

Going beyond trust in e-commerce site and conceptualizing social commerce trust as a multidimensional variable is also consistent with the trust transfer theory [92]. According to this theory, trust transfer can occur between different kinds of sources. For example, consumers can perceive a close relationship between the target (e.g., e-commerce sites) and another source of trust (e.g., social media), and such a relationship can induce trust transfer. Previous studies have also found that a consumer's trust in one object can be transferred to that individual's trust in another object $[5,53,103]$. Because the trust transfer process is dynamic and evolving [53, 92], linking different trust perspectives (i.e., trust in different objects) can provide a deeper understanding of social commerce trust.

To summarize, trust has been mainly studied as single objects focusing on e-commerce sites and customers. However, previous literature has not paid much attention to trust in social media and trust in social commerce features and failed to capture consumers’ overall trust toward e-commerce. Figure 1 shows the trust domain in e-commerce and research gaps (represented in gray areas). To fill these gaps, our study conceptualizes trust in social commerce and identify its relevant dimensions based on the social-technical theory. Below we describe the social-technical theory in more details. 


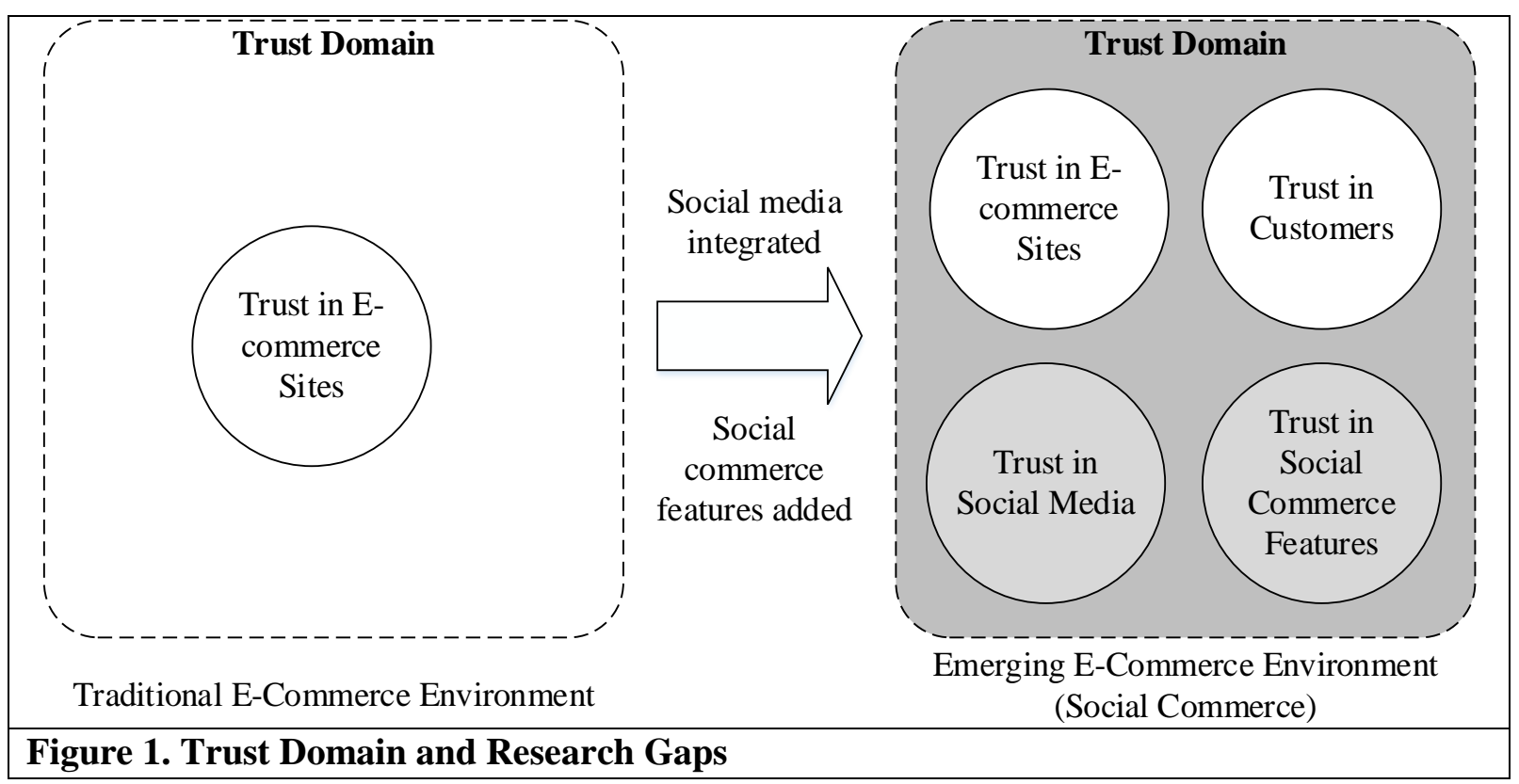

\section{Social Commerce: The Social-Technical Perspective}

Social-technical theory posits that a system could consist of two sub-systems: the social sub-system and the technical sub-system (Figure 2) [8]. Briefly, the technical sub-system comprises the processes and technology that enable users to transform inputs into outputs and complete specific tasks within the system. In contrast, the social sub-system comprises the users, knowledge, values, relationships, and reward system. These two sub-systems do not stand alone; rather, they are correlative and should work in harmony for optimized system performance [8, 9]. From this perspective, people and technology play important roles in driving the performance of a system, as they largely determine the fit between the two sub-systems. 


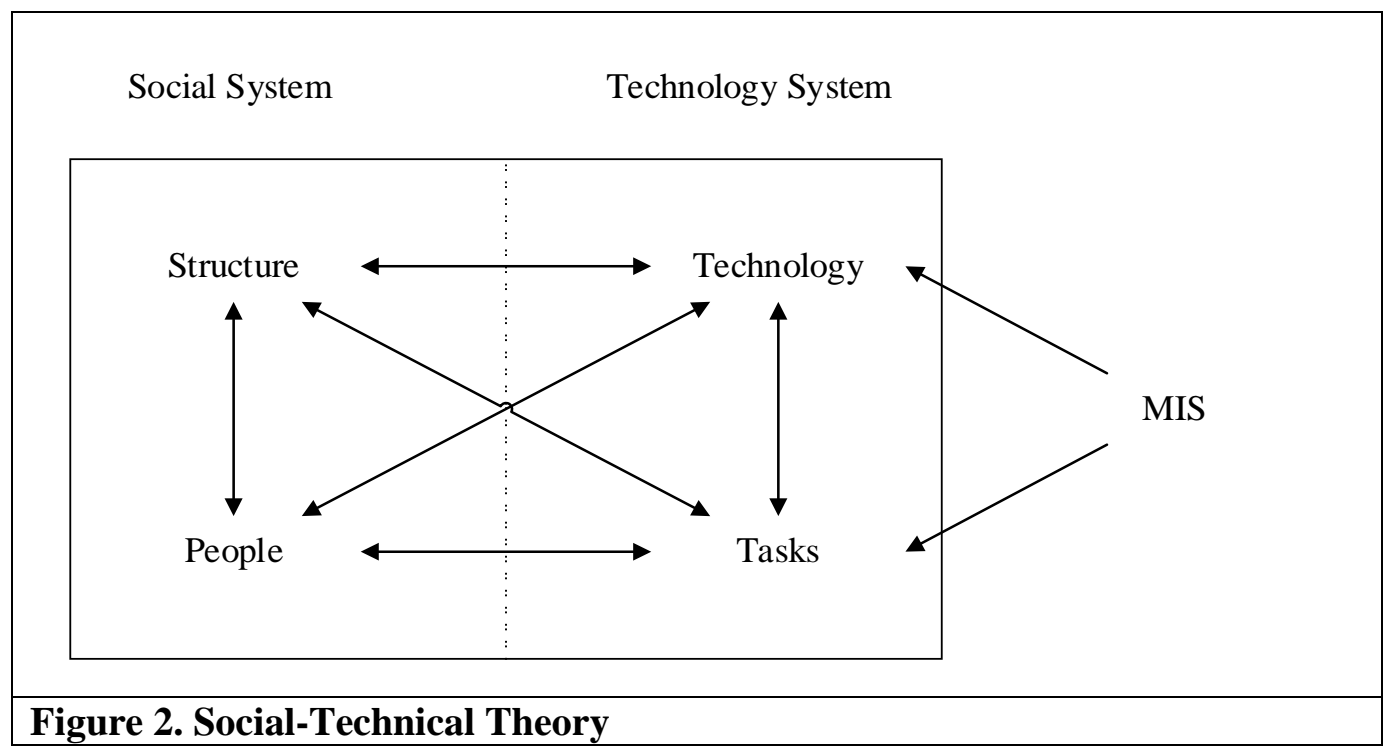

This theory is highly applicable to social commerce, which is largely driven by people and web technology and involves the two sub-systems outlined above. People (i.e., social media users, consumers, and sellers) and organizational (i.e., a group, online brand community, and fan pages) components comprise the social sub-system of social commerce that supports social interactions and social relationships; facilitates social support; and develops users' trust in and commitment to an organization $[9,63,74,106,110]$. The web technology (i.e., e-commerce sites, social media and social commerce features) and process components make up the technical sub-system of social commerce that drives social commerce activities such as commercial information sharing and customer reviews $[40,63,110]$. According to social-technical theory, changes in task and technology is not limited to the technical system, but also impact structure and people in the social system (see Figure 2). By integrating social commerce features and social media, e-commerce sites change the technology environment, and thus providing the affordances enabling consumers to conduct new tasks (i.e., new consumer behaviors such as product information sharing). Such changes can also impact people and task structure (i.e., the way in which consumers interact on e-commerce sites) [8]. In such a scenario, the technical sub-system serves as the foundation for the social sub-system in the social commerce environment, as web technology enables people to interact with one another and to develop and 
maintain social relationships. On the other hand, the social sub-system may trigger advances in the technical sub-system of social commerce, as both people and organizations demand high-quality social relationships, social support, and social interactions, which can be achieved by improving technology capabilities. In social commerce, these two sub-systems have been shown to work mutually and to have a good fit $[47,48,111]$. These two sub-systems are thus beneficial to consumers, by improving their shopping experience and purchase decisions [12], as well as to businesses, in gaining a competitive advantage [108]. Therefore, social-technical theory is an appropriate theoretical lens because it can help understand how different dimensions work together to form consumers' social commerce trust. Drawing from social-technical theory, we argue that people and technology are the primary components that drive social commerce and can best represent the two sub-systems of social commerce.

Our study is set in a specific social commerce research context that integrates social media into traditional e-commerce sites and facilitates social commerce features (i.e., customer reviews and sharing through social media). We focus on consumers who have experience with these social commerce features. Therefore, consumers best represent the people component, as they are the primary people who use these social media features. Technology is best represented by e-commerce platforms and social media. Accordingly, we identify its dimensions below. Figure 3 provides an overview of social commerce trust, and below we identify its dimensions in detail.

\section{Definition of Social Commerce Trust}

Individuals’ subjective beliefs are the key factors that drive their trust in a specific object such as a group, an organization, or a website, and serve as a foundation for defining consumer trust [54, 63, 72]. For example, Kim, Ferrin, and Rao [54] refer to consumer trust as “a consumer's subjective belief that the selling party or entity will fulfill its transactional obligations as the consumer understands them" in the context of e-commerce. Consumer trust is defined with a focus on individuals' subjective beliefs in online transactions with e-vendors, as e-commerce traditionally concentrates on the interaction 
between companies and consumers. From this perspective, the definition of consumer trust should switch its focus to subjective beliefs in consumers and social web technology, reflecting the advancement of social commerce. Therefore, in this study, social commerce trust refers to consumers' subjective beliefs that other consumers are trustworthy and that web technology (i.e., e-commerce sites, social media, and social commerce features) is reliable to perform social commerce behaviors. Social commerce trust thus occurs in a multi-dimensional context including people and technology dimensions. Accordingly, we model consumers' overall trust in social commerce as a second-order construct by capturing trust in different objects (e.g., trust in sites, trust in social media, trust in consumers) as first-order constructs [29]. Such studies are important to understand how different dimensions contribute to consumers' trust in e-commerce / social commerce overall.

There are three issues to note in our definition of social commerce $\operatorname{trust}^{6}$. First, while social commerce trust captures trust in different objects, these different dimensions may not come together. Since e-commerce sites are the main platforms to which social media and social commerce features are integrated, trust in e-commerce sites probably come first. Then as consumers use various social commerce features and share information via social media, they will form their perception regarding whether they are trustworthy. Therefore, trust in social commerce features and trust in social media probably come next. Lastly, through interacting with others, consumers will develop their trust beliefs toward their peers. Therefore, trust in consumers may come last. Also note that such a process is recursive rather than linear. For example, as consumers use social commerce features more often, their trust in social commerce features may transfer to their trust in e-commerce sites, and thus enhancing their social commerce trust as a whole.

Second, by “other consumers”, we mean those consumers from the same e-commerce sites ${ }^{7}$. Third,

\footnotetext{
${ }^{6}$ We thank one reviewer for pointing these issues out to help better understand our conceptualization of social commerce trust. Please note that the trust formation process, among the various factors, is not a part of this study.

${ }^{7}$ For example, the context of our study is Amazon.com. Therefore, "other consumers" refer to other consumers from Amazon.com. We thank one reviewer for pointing this issue out.
} 
social commerce behaviors refer to seeking and sharing product information, which are empowered by social commerce features and social media. Figure 3 provides an overview of social commerce trust, and below we identify its dimensions in detail.

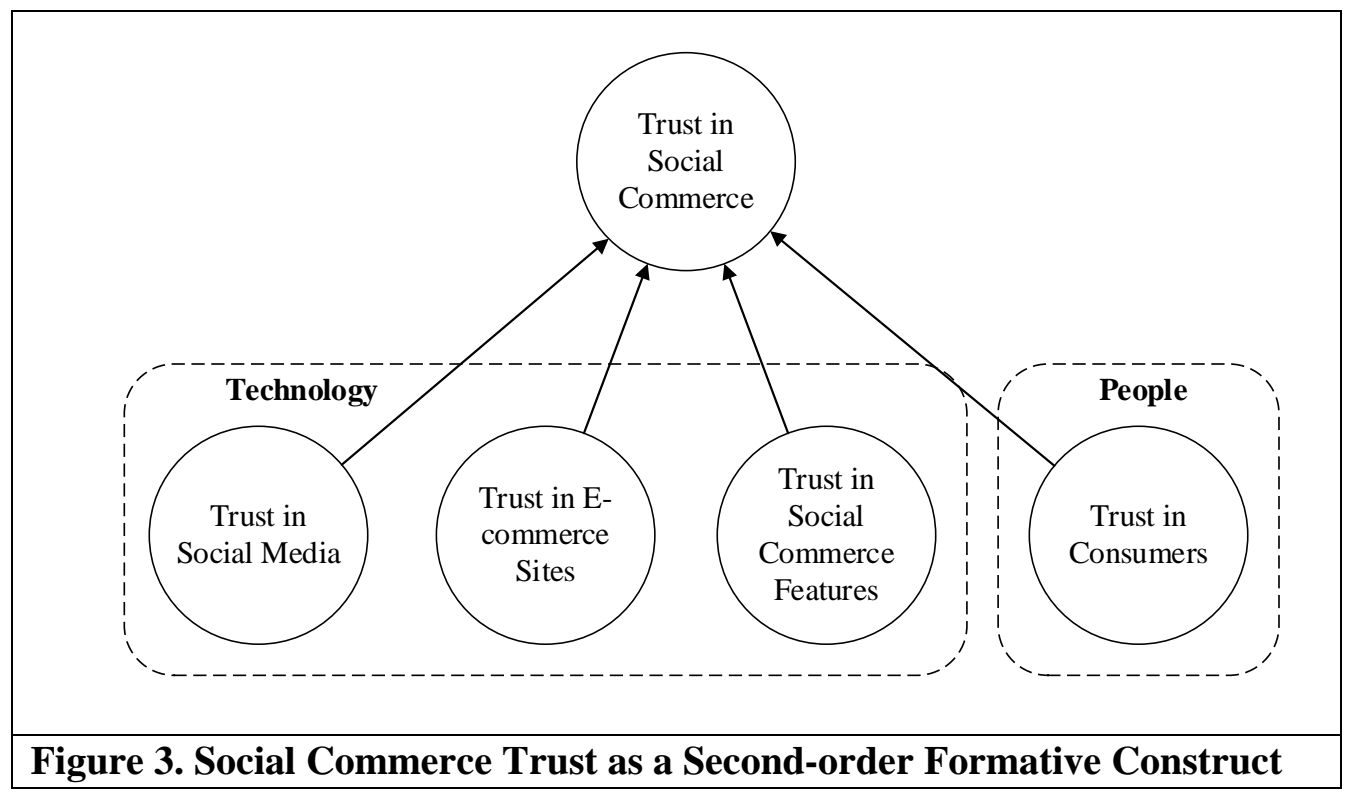

\section{The people dimension}

Consumers have been identified as a key component of social commerce [110,111]. Consumers may exchange information about products and services, give or receive advice and product recommendations, and share first-hand shopping experiences in the social commerce environment [63]. From this perspective, consumers are the primary driver for social commerce, and they create its economic value [91]. The importance of consumers is also evident in the social commerce literature (e.g., [74, 106, 108]). Consumers' subjective beliefs about other consumers comprise one dimension of social commerce trust. Consumers' positive subjective beliefs that other consumers are honest and provide trustworthy user-generated content determine social commerce trust. Therefore, to capture this dimension of social commerce trust, we use a specific construct: trust in consumers.

\section{The technology dimensions}

Technology has been traditionally identified as a dimension of trust $[54,56,71]$. In our study, 
technical capabilities of social commerce mainly evolve from social media and e-commerce platforms [110]. These technology tools for social commerce work together, provide sufficient support for social commerce features and support consumers' social commerce activities such as ratings, customer review, and sharing. From this perspective, consumers' trust beliefs in all social commerce tools comprise social commerce trust.

First, social media serves as a foundation for the technical capability of social commerce, based on studies of social commerce that have measured trust in a single-dimensional way [41, 63, 74]. In these studies, trust captures individuals' trust beliefs in specific social media. Accordingly, our study uses trust in social media to capture consumers' trust beliefs in general social media, which is currently the primary component of trust in social commerce. Second, considering our specific social commerce research context, trust in e-commerce sites contributes to the technology dimension of social commerce. Trust in e-commerce sites has been identified as a key dimension of consumer trust in the traditional e-commerce context [54, 71], but it has not been integrated into consumer trust in social commerce, as mentioned earlier. Given that social commerce is the intersection of social media and e-commerce, trust in e-commerce sites is viewed as another key dimension and captures consumers' trust beliefs in e-commerce sites. Finally, social commerce features and e-commerce platforms need to work mutually to provide consumers with the ability to participate in social commerce activities. Therefore, consumers' trust beliefs in social commerce features also contribute to social commerce trust from the technology perspective. In summary, to best capture the technology dimension of social commerce trust, we use three constructs: trust in social media, trust in e-commerce sites, and trust in social commerce features.

\section{Research Model and Hypotheses Development}

Our study proposes a social commerce trust-based consumer decision-making model in the context of social commerce by 1) examining the effects of social commerce trust on e-commerce outcomes, and 2) identifying the antecedents of social commerce trust. 


\section{E-commerce Outcomes: Building Consumer Satisfaction and Triggering Purchasing Behaviors}

In our study, we propose that e-commerce outcomes include e-commerce satisfaction and purchasing behavior. E-commerce satisfaction refers to the extent to which individuals feel satisfied with all aspects of an e-commerce system [73]. Purchasing behavior refers to the frequency and willingness to purchase on certain e-commerce sites. Satisfaction is an important e-commerce outcome as it can lead to consumers' ongoing intention to visit e-commerce sites [28]. Previous studies have examined how various factors lead to e-commerce satisfaction [50] (see Jaiswal, Niraj, and Venugopal [50] for a summary). Purchasing behavior is also important as it can generate revenue for e-vendors.

\section{The effects of social commerce trust}

As discussed above, our conceptualization of social commerce trust includes both technology and people dimensions based on social-technical theory. The literature demonstrates that trust in vendors can increase consumers' satisfaction, intention to engage in transactions, and loyalty toward e-vendors in e-commerce [16, 36, 71]. Essentially, trust can facilitate a comfortable environment and help reduce consumers' perception of risk associated with shopping with e-vendors [26, 82]. In social commerce, consumers' trust in peer consumers is also important as they interact with each other to exchange product-related information. $\mathrm{Ng}$ [74] argues that trust in a social network community can increase consumer intention to purchase in social commerce. As a multi-dimensional construct, social commerce trust influences consumer decision making as a comprehensive process combining the cognitive and affective process by incorporating the effects of its dimensions [55, 71, 72]. With high social commerce trust, consumers perceive that e-commerce sites, and social media integrated and social commerce features perform reliably and meet their requirements during the shopping process. Consumers will also perceive that other consumers are reliable and care about their needs, thus leading to positive perceptions of websites. Therefore, consumers perceive that e-commerce sites are a comfortable environment for shopping and feel satisfied with e-commerce sites. Thus, they are more willing to make purchases. To summarize, we hypothesize that: 
H1a: Social commerce trust is positively related to e-commerce satisfaction.

H1b: Social commerce trust is positively related to purchasing behavior.

The literature shows that e-commerce satisfaction has a positive effect on purchase intention [28]. Consumers' e-commerce satisfaction reflects their perceptions of e-vendors' effective performance during past experiences. Thus, when consumers feel satisfied with their past experiences, they are more likely to make purchases with e-vendors in future. Therefore, we hypothesize that:

H2: E-commerce satisfaction is positively related to purchasing behavior.

\section{Antecedents of Social Commerce Trust}

Given that the primary focus of this paper is consumers' social commerce trust, and considering our specific research context, we primarily draw from the literature on social commerce and identify two key antecedents: social support and customer review quality.

Social support is defined as "information leading the subject to believe that he is cared for and loved, esteemed, and a member of a network of mutual obligations” [20, p. 300]. It can be formed by the exchange of resources (i.e., verbal and nonverbal messages) between two or more individuals. Social support has been identified as a primary factor that distinguishes social commerce from traditional ecommerce [38, 63]. Social support could be facilitated through the transmission of information shared by individuals, and the content of information determined the type of social support. Liang, $\mathrm{Ho}, \mathrm{Li}$, and Turban [63] brought up social support in social commerce and measured it using two dimensions: informational support and emotional support. Informational support comes in the form of sharing product-related information or providing advice, referrals, and recommendations. Emotional support comes in the form of sharing individual emotion/mood states or expressing concerns, empathy, and caring to one another [95]. Therefore, consumers can obtain different types of social support mainly based on the nature of the content (e.g., knowledge-featured content and emotion-featured content) shared by other consumers on various social media-based platforms. Subsequently, social support has gained much attention, and many scholars argue that social support is a key factor that largely 
determines consumers' intentions to use social commerce features on various platforms $[40,106]$. With social support, social commerce has become a popular source for consumers to exchange resources and help one another with purchasing decisions.

In addition, information quality has traditionally been viewed as one of the prerequisites for successful e-commerce $[22,23]$. It refers to the degree to which certain technology provides helpful information for individuals completing certain tasks [101]. User-generated content is another key component of social commerce that plays an important role in driving social commerce $[40,47,110]$. The quality of user-generated content is very important for sufficient product evaluations and accurate purchasing decisions. Considering our specific research context, we use customer review quality and define it “consumers’ perceived overall quality of information provided by other consumers”.

\section{Social support}

Social support has been found to motivate users to participate in social commerce activities, facilitating social relationships among users [40,63, 106]. For example, with stronger social support, users are more likely to interact with one another and exchange knowledge about a specific issue, as well as express concerns in social media - based communities, which could lead to higher perceptions of site performance [64]. Accordingly, in our specific research context, social support could be acquired by consumers through social commerce activities such as customer reviews and social media sharing. With strong social support, consumers would be able to gain knowledge about products, services, or brands, and enhance their understanding of shopping-related issues, thus improving their subjective trust belief in social commerce. In other words, social support is important in building trust because it helps consumers sufficiently evaluate products through observing others' product knowledge and purchasing experiences, and overcoming perceptions of uncertainty and risk in the purchasing process $[55,72]$. Meanwhile, social support creates a supportive environment for consumers in which they feel more confident in making accurate purchase decisions [12, 63]. From this perspective, social support could increase consumers' trust beliefs in social commerce through their psychological perceptions 
[54], thus formatting social commerce trust. In summary, when consumers experience social support, they may receive helpful shopping advice from others and feel cared for by other consumers. In such a scenario, social support can not only meet consumers’ needs (e.g., need for relevant information), but also make them feel that other consumers act in their interests, thus building social commerce trust. Therefore, consumers' perceptions of social commerce trust would be higher when they experience stronger social support in the context of social commerce. Thus, we hypothesize:

H3: Social support is positively related to social commerce trust.

\section{Customer review quality}

Previous studies have proposed that information quality is an important factor in influencing individuals' satisfaction and technology adoption [29, 101]. In e-commerce, information comes from e-commerce vendors and is critical because it provides value to consumers [73] and reduces the uncertainty related to the shopping process. Jaiswal, Niraj, and Venugopal [50] also argue that information quality can increase consumer satisfaction and enhance loyalty toward e-commerce sites.

In contrast, in social commerce, information (i.e., product reviews) comes from other consumers. In such a scenario, consumers probably perceive that reviews from other consumers have high quality when these reviews are relevant and helpful [47]. Individuals may thus feel that these high-quality customer reviews can meet their needs and support their shopping processes. Further, when reviews from other consumers are reliable, up to date, and can meet their shopping needs, consumers are more likely to perceive that social commerce environment is beneficial. Thus, with a higher level of customer review quality, the social commerce environment is more likely to be accepted and used by consumers, enhancing their social commerce trust. Thus, we hypothesize that:

H4: Customer review quality is positively related to social commerce trust.

\section{A Social Commerce Trust-based Consumer Decision-making Model}

We develop a theoretical model describing a consumer's social commerce trust-based decision making. It posits that social support and customer review quality influence social commerce trust, 
which in turn influences consumers' decision-making processes consisting of e-commerce satisfaction and purchasing behaviors. Figure 4 depicts our research model.

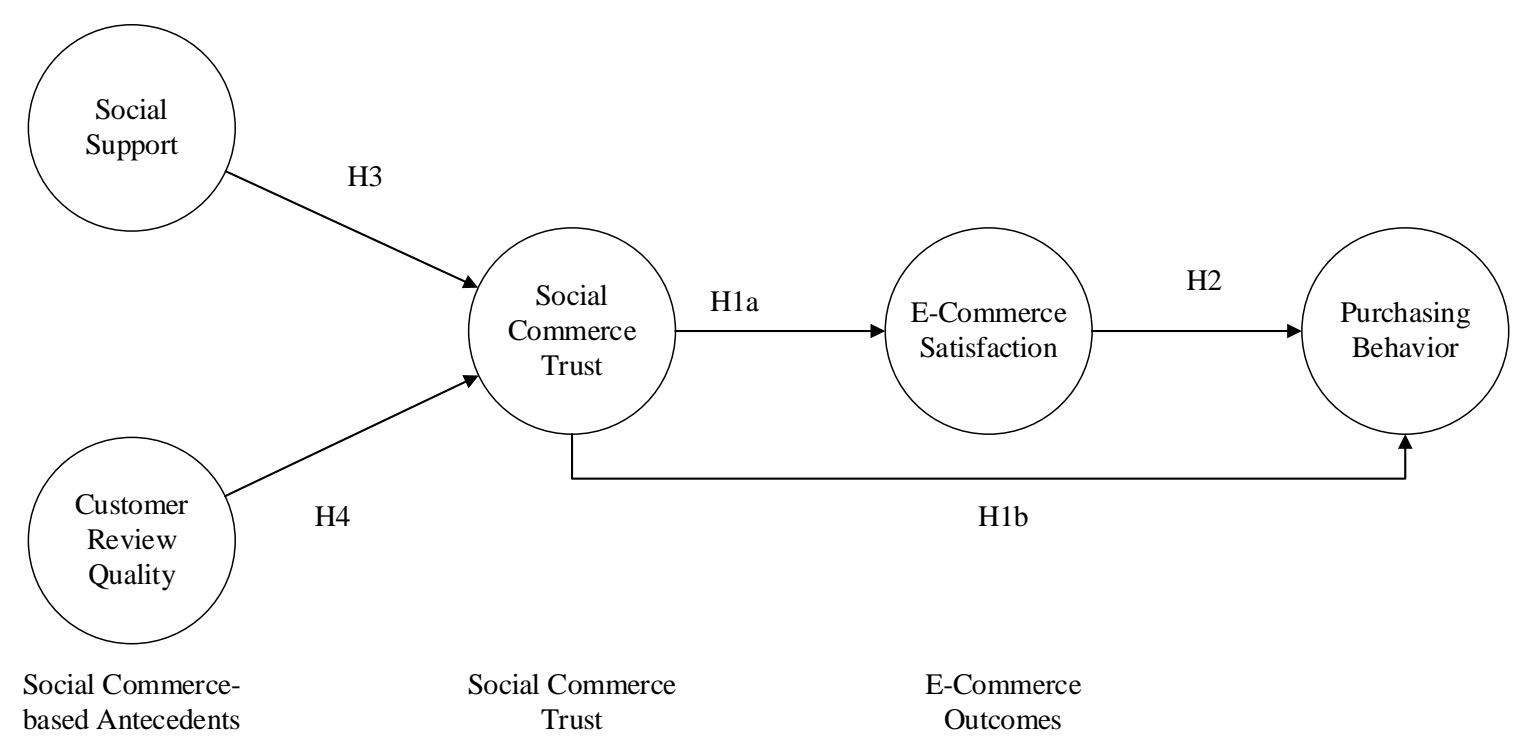

Figure 4. A Social Commerce Trust-based Consumer Decision-making Model

\section{Research Method}

Our study collected data from an online survey taken by Amazon consumers in the United States (US). Below, we describe our data collection procedures, measurements, data analysis, and results.

\section{Data Collection Procedures and Participants}

A survey company was employed to recruit participants. The survey company maintains various channels (e.g., user registration, collaboration with business partners) to recruit a variety of samples. Several approaches, such as a survey hub and relevant identification (ID) with quality assurance questions were used to detect fraudulent or duplicate answers. Each participant was assigned a unique ID so the survey company could keep track of who participated in the survey. During the sampling, survey companies firstly selected the qualified individuals (i.e., e-commerce consumers in this study) and then sent out online survey invitations through systematic sampling. For example, assume the size of the national panel was about 100,000 and about 400 participants were planned to be selected. Then invitations of the survey were sent out with the interval of 250 users. 
Participants only qualified for the survey if they had 1) shopped on Amazon at least three times in the previous three months (i.e., make one purchase on average per month); 2) used Facebook, Twitter or Pinterest many times each week; and 3) had engaged in social commerce behaviors in the previous three months. Specifically, for the third criteria, we asked participants whether they had been involved in the following activities: 1) read other customers' ratings and reviews, 2) rate and/or comment on products purchased on Amazon, and 3) "Share" product information on social media (i.e., Facebook, Twitter, and Pinterest). Our survey contains questions dealing with social commerce features. To clarify its concept, we inserted the following statement in the beginning of our survey:

“On Amazon, social commerce features include customer reviews (e.g., ratings \& comments on products) and "Share” on social media (e.g., Facebook, Twitter and/or Pinterest). In this survey, we use the term "social media features" to refer to those features including customer rating \& reviews, or sharing product information on social media such as Facebook, Twitter, and Pinterest.”

Participants were asked to answer most questions from the survey based upon their experiences in Amazon. The only exception was trust in social media, and participants were instructed to answer these questions based upon their experiences in social media (i.e., Facebook, Twitter, and Pinterest). The data collection process lasted for about a month. In total, we received 903 valid responses. Demographic information about participants is provided in Table 1. Non-response bias was evaluated by assessing differences between early and late participants, and the results indicated that there were no significant differences among their demographic backgrounds.

Table 1. Sample Demographic Information ( $=903)$

\begin{tabular}{|l|c|c|c|}
\hline Ethnicity & & Age & \\
\hline White & $80.51 \%$ & $18-19$ & $.55 \%$ \\
\hline Black or African American & $9.08 \%$ & $20-29$ & $13.07 \%$ \\
\hline American Indian or Alaska Native & $.44 \%$ & $30-39$ & $22.26 \%$ \\
\hline Asian & $3.54 \%$ & $40-49$ & $16.94 \%$ \\
\hline Hispanic & $5.65 \%$ & $50-59$ & $25.47 \%$ \\
\hline Other & $.78 \%$ & 60 or older & $21.71 \%$ \\
\hline Education & & Gender (\% of Female) & $53.71 \%$ \\
\hline
\end{tabular}




\begin{tabular}{|l|c|c|c|}
\hline Less than high school & $1.44 \%$ & $\begin{array}{l}\text { Times of Shopping on Amazon } \\
\text { during the last three months }\end{array}$ & \\
\hline High school graduate & $16.17 \%$ & $4-6$ times & $44.08 \%$ \\
\hline Some college & $24.47 \%$ & $7-9$ times & $20.49 \%$ \\
\hline 2 year degree & $12.85 \%$ & $10-12$ times & $16.17 \%$ \\
\hline 4 year degree & $31.34 \%$ & More than 13 times & $19.16 \%$ \\
\hline Professional degree & $11.96 \%$ & Years shopping on Amazon & 6.46 (SD 3.89) \\
\hline Doctorate & $1.77 \%$ & Years using social media & 6.58 (SD 3.20) \\
\hline
\end{tabular}

\section{Measurement}

Our measures were adapted from the literature (see Table 2 for complete measurement). Specifically, items of social support were adapted from Liang, Ho, Li, and Turban [63]. Social support was measured as a second-order reflective construct consisting of informational support and emotional support. Customer review quality was adapted from Huang and Benyoucef [47]. Social commerce trust was measured as a second-order formative construct, including trust in social media, trust in e-commerce site, trust in social commerce features, and trust in consumers. These were measured with items from the work of Liang, Ho, Li, and Turban [63] and modified to fit the research context of this study. The focus of this study is to propose a new approach to model social commerce trust, rather than to develop new items. In other words, our study adapted existing items to new contexts (i.e., different objects of trust $)^{8}$. Items of e-commerce satisfaction were adapted from Molla and Licker [73], and items of purchasing behavior were adapted from items of purchase intention $[24,105]$ to measure consumers’ self-reported purchasing on Amazon. These items were rated on a seven-point Likert scale from “Strongly Disagree” to "Strongly Agree”.

\section{Data Analysis and Results}

As all the variables were collected in one survey, we first assessed the potential for common method bias (CMB) [84]. First, a Harmon one-factor analysis was conducted. The results showed that six

\footnotetext{
8 Therefore, we did not pre-test our scales. On the other hand, during our data collection, when the number of complete records reached about 100, we paused the data collection and assessed the measures. Our analysis showed that measures have good convergent and discriminant validity. Then we proceeded until the whole data collection finished. Nevertheless, we admit that it is a limitation of our study.
} 
factors were present and that the most variance explained by a single factor was $39.03 \%$. Second, a marker variable was used as a surrogate for method variance to partial out any method bias [66]. Following adjustment, all significant correlations remained significant. Therefore, we concluded that CMB was unlikely to be a serious concern for our study.

Our model was tested with partial least squares (PLS). SmartPLS [86] was used with the bootstrap re-sampling method (using 1000 samples) to determine the significance of the paths. PLS was used in our study for two main reasons. First, it works with weighted composites, and is compatible with formative measurement [18]. In contrast, formative measurement can result in identification problems in covariance-based structural equation modeling [99]. Second, our measurements were not normally distributed, and Shapiro-Wilk tests were significant. According to Hair Jr and Hult [37], PLS is more appropriate with non-normally distributed data.

We first evaluate the measurement model. As shown in Table 2, each item loaded significantly on its respective construct, with none of the loadings below .50 [49]. The composite reliabilities (CRs) were greater than .70, and the average variance extracted (AVE) was over .50 (Table 2). Therefore, convergent validity was supported [31]. Discriminant validity was also confirmed by ensuring that the correlations between constructs were below .85 [10]; and for each construct, the square root of its AVE exceeded all correlations between that factor and any other construct (Table 3). Therefore, our measures demonstrated good psychometric properties ${ }^{9}$.

Table 2. Item descriptive statistics

\begin{tabular}{|c|c|c|c|c|c|}
\hline Items & Mean & SD & Loading & CR & AVE \\
\hline \multicolumn{6}{|l|}{ Social Support } \\
\hline \multicolumn{6}{|l|}{ Informational Support } \\
\hline $\begin{array}{l}\text { Consumer-generated content enables me to evaluate } \\
\text { products I want to buy. }\end{array}$ & 6.30 & .85 & .87 & .92 & .79 \\
\hline $\begin{array}{l}\text { Consumer-generated content enables me to make the right } \\
\text { purchases. }\end{array}$ & 6.13 & .89 & .91 & & \\
\hline Consumer-generated content enables me to support my & 6.06 & .96 & .89 & & \\
\hline
\end{tabular}

${ }^{9}$ We also conducted confirmatory factor analysis. The model had good fit indices: $\chi^{2}=1899.51$, d.f. $=428 ; \mathrm{CFI}=.94 ; \mathrm{TLI}=.93$, RMSEA $=.06$, SRMR $=.05$. Items also have acceptable loadings, CRs, and AVEs, and showed good discriminant validity. 
purchase decisions.

\section{Emotional Support}

Consumer-generated content comforts and encourages me to make purchase decisions.

$\begin{array}{llllllll}\text { Consumer-generated content makes me feel more } & 6.12 & .93 & .89\end{array}$

confident in making purchase decisions.

$\begin{array}{lllll}\text { Consumer-generated content brings me a lot of enjoyment } & 5.53 & 1.26 & .85\end{array}$

when I am shopping.

Customer review quality

The information provided by other consumers on Amazon

is-accurate.

The information provided by other consumers on Amazon is-relevant.

The information provided by other consumers on Amazon is-complete.

The information provided by other consumers on Amazon is-reliable.

$\begin{array}{lllll}\text { The information provided by other consumers on Amazon } & 5.94 & .96 & .95\end{array}$

is-readily usable.

$\begin{array}{lllll}\text { The information provided by other consumers on Amazon } & 5.76 & 1.03 & .85\end{array}$

is-timely.

\section{Social Commerce Trust}

Trust in social media

The performance of social media always meets my expectations.

Social media can be counted on as good sites.

$\begin{array}{lll}5.68 & .99 & .87\end{array}$

Social media is reliable.

Trust in e-commerce site

$\begin{array}{llllllllll}\text { The performance of Amazon always meets } & \text { my } & 5.99 & 1.02 & .87 & .93 & .81\end{array}$ expectations.

$\begin{array}{llllll}\text { Amazon can be counted on as a good e-commerce } & 6.19 & .89 & .91\end{array}$ website.

Amazon is a reliable e-commerce website.

Trust in social commerce features

The performance of social media features in Amazon

Social media features could be counted as good features in Amazon.

Social media features are reliable in Amazon.

Trust in social commerce consumers

I believe other consumers on Amazon are honest.

I believe other consumers on Amazon care about others

$\begin{array}{lll}6.27 \quad .88 & .92\end{array}$

$5.44 \quad 1.23 \quad .93$

all the time.

$8.31 \quad 1.15 \quad .88$


$\begin{array}{lllll}\text { I believe other consumers on Amazon are dependable. } & 8.49 & 1.08 & .93\end{array}$

$\begin{array}{lllll}\text { I believe other consumers on Amazon provide good } & 8.79 & .951 & .86\end{array}$

comments.

\section{E-Commerce Satisfaction}

$\begin{array}{lllllll}\text { I feel satisfied with my overall experiences with Amazon. } & 9.51 & .723 & .89 & .93 & .78\end{array}$

$\begin{array}{lllll}\text { I feel pleased about my overall experiences with Amazon. } & 9.43 & .757 & .92\end{array}$

$\begin{array}{llll}\text { I feel content about my overall experiences with Amazon. } & 9.37 & .797 & .88\end{array}$

$\begin{array}{llllll}\text { I feel delighted about my overall experiences with } & 9.13 & .997 & .85\end{array}$

Amazon.

\section{Purchasing Behavior}

I usually purchase products from Amazon.

$6.21 \quad .892 \quad .89$

$\begin{array}{lll}6.29 & .884 \quad .87\end{array}$

I frequently shop from Amazon.

$\begin{array}{lll}6.34 & .833 \quad .88\end{array}$

I would like to purchase products from Amazon.

Table 3. Correlation between Constructs and Square-root of AVEs (on-diagonal)

\begin{tabular}{lccccccccc}
\hline & 1 & 2 & 3 & 4 & 5 & 6 & 7 & 8 & 9 \\
\hline 1 Customer Review Quality & $\mathbf{. 8 6}$ & & & & & & & & \\
2 E-commerce satisfaction & .57 & $\mathbf{. 8 8}$ & & & & & & & \\
3 Emotional support & .63 & .55 & $\mathbf{. 8 8}$ & & & & & & \\
4 Informational Support & .59 & .56 & .75 & $\mathbf{. 8 9}$ & & & & & \\
5 Purchase Behavior & .54 & .61 & .57 & .55 & $\mathbf{. 8 8}$ & & & & \\
6 Trust in consumers & .72 & .51 & .64 & .57 & .46 & $\mathbf{. 9 0}$ & & & \\
7 Trust in social media & .60 & .37 & .54 & .44 & .38 & .62 & $\mathbf{. 9 3}$ & & \\
8 Trust in social commerce features & .61 & .50 & .62 & .55 & .45 & .65 & .69 & $\mathbf{. 9 3}$ & \\
9 Trust in e-commerce site & .54 & .62 & .52 & .53 & .54 & .54 & .43 & .60 & $\mathbf{. 9 0}$ \\
\hline
\end{tabular}

We then assessed second-order constructs. As shown in Panel A of Figure 5, the loadings of social support were .92 and .94 for informational support and emotional support, respectively, showing good convergent validity. For social commerce trust (Panel B in Figure 5), the weights of first-order trust constructs were all significant, supporting our conceptualization of social commerce trust. 


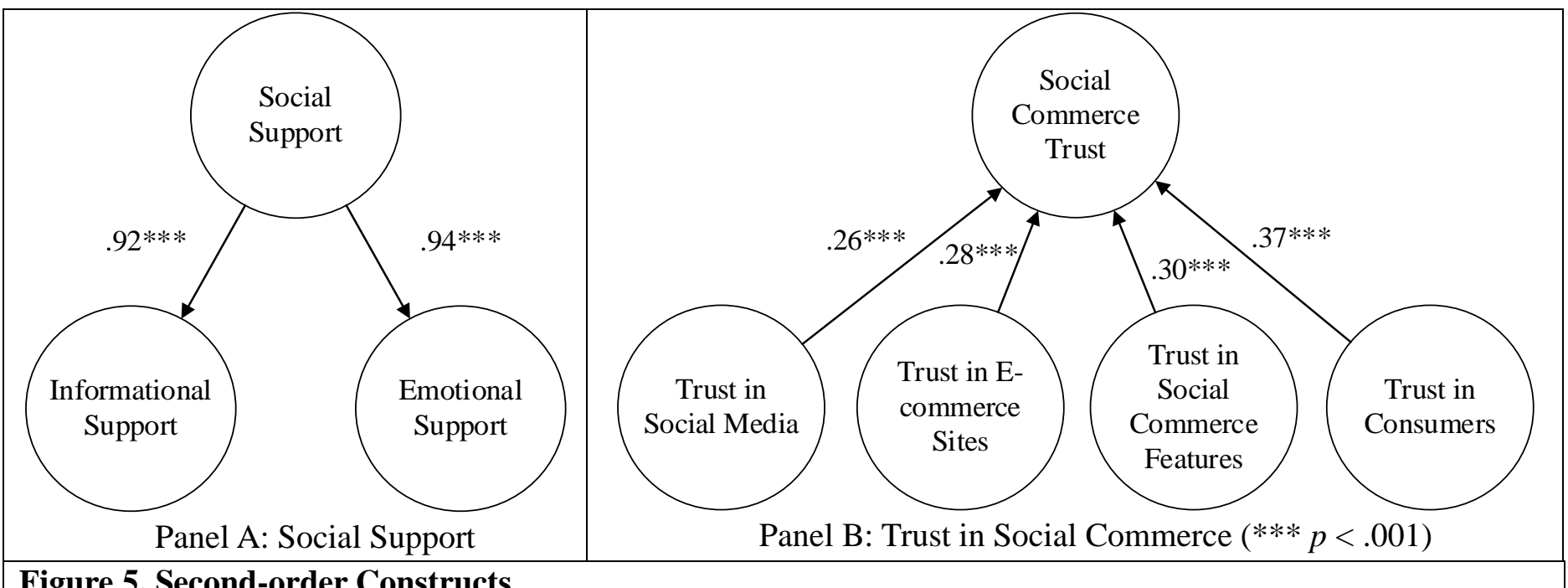

\section{Figure 5. Second-order Constructs}

In the second stage assessing the structural model [49], path coefficient and $\mathrm{R}^{2}$ measures were examined. H1a, that social commerce trust is positively associated with e-commerce satisfaction, was supported $(\beta=.59, p<.001)$. H1b, which posits that social commerce trust is positively related to purchasing behavior, was also supported $(\beta=.28, p<.001)$. H2 suggests that e-commerce satisfaction is positively related to purchasing behavior. This hypothesis was supported $(\beta=.44, p<.001)$. H3 argues that social support is positively associated with social commerce trust, and this hypothesis was supported $(\beta=.40, p<.001)$. Finally, H4, that customer review quality is positively associated with social commerce trust was also supported $(\beta=.49, p<.001)$. All the hypotheses are supported based on the research results, as shown in Table 4. 


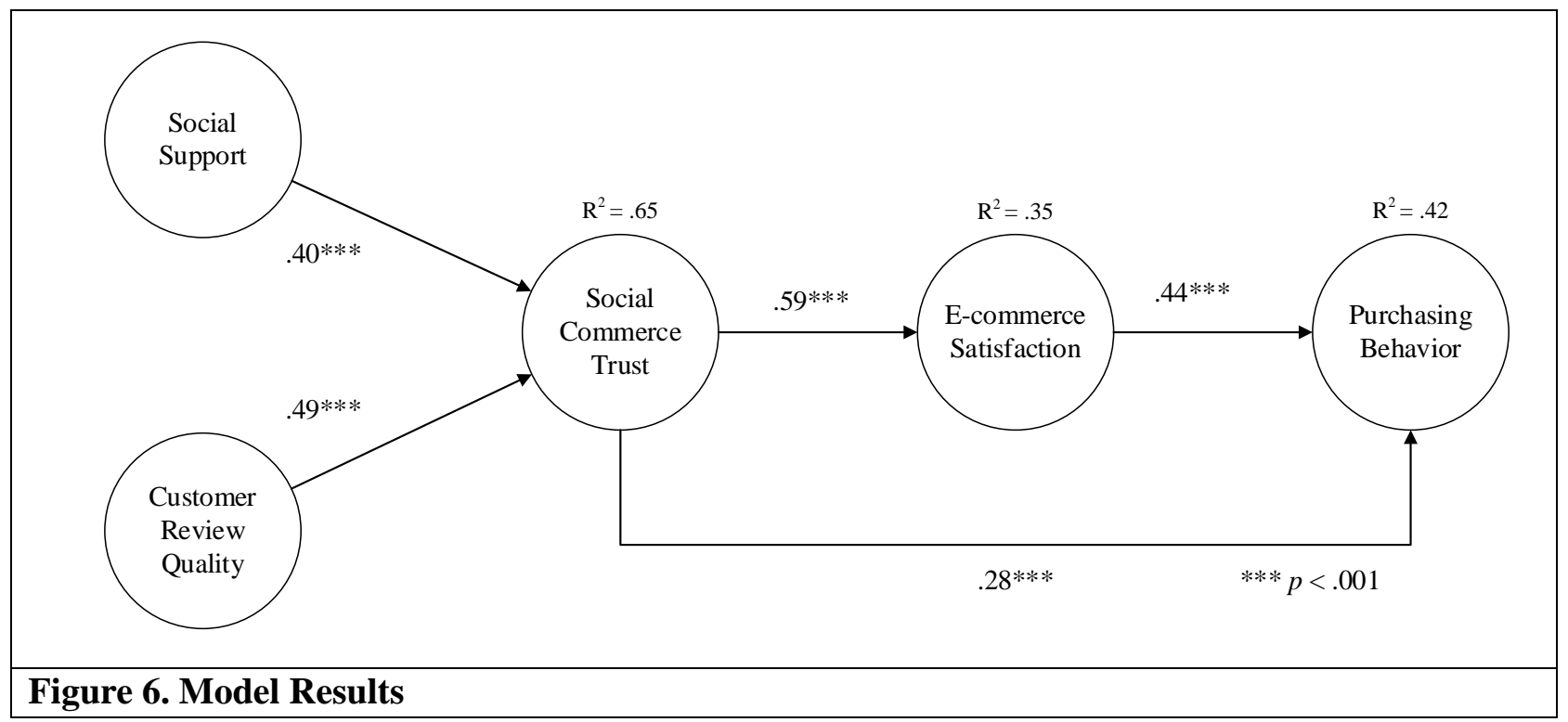

Table 4. Summary of Hypotheses Testing

\begin{tabular}{|l|c|c|c|}
\hline Hypothesis & Path Coefficient & T-value & Supported? \\
\hline H1a: Social commerce trust $\rightarrow$ E-commerce satisfaction & .59 & $23.10^{* * *}$ & Yes \\
\hline H1b: Social commerce trust $\rightarrow$ Purchase behavior & .28 & $8.75^{* * *}$ & Yes \\
\hline H2: E-commerce satisfaction $\rightarrow$ Purchase behavior & .44 & $12.02^{* * *}$ & Yes \\
\hline H3: Social support $\rightarrow$ Social commerce trust & .40 & $11.75^{* * *}$ & Yes \\
\hline H4: Customer review quality $\rightarrow$ Social commerce trust & .49 & $15.06^{* * *}$ & Yes \\
\hline
\end{tabular}

$* p<.05, * * p<.01, * * * p<.001$

We also assessed the predictive quality of our model using the Stone-Geisser $\left(Q^{2}\right)$ test [33, 93]. The model has estimation relevance when $\mathrm{Q}^{2}$ is positive; otherwise, the model lacks estimation relevance, resulting in a doubtful determination of the latent variable. The $\mathrm{Q}^{2}$ values were .77 for emotional support, .79 for informational support, .73 for customer review quality, .86 for trust in social media, .80 for trust in e-commerce site, .87 for trust in social commerce features, .81 for trust in consumers, .78 for e-commerce satisfaction, and .77 for purchasing behavior. Therefore, our model had good predictive relevance overall.

\section{Testing the Competing Model}

Lastly, we compare the proposed model where social commerce trust is model as a second-order formative construct with its competing model where social commerce trust is model as four separate 
first-order constructs. Our comparison follows two criteria: (1) whether each relationship is statistically significant, and (2) model parsimony.

For the first criterion, our results (Figure 7) show that the relationships between social support/consumer review quality and trust are all significant. However, not all the relationships between trust and e-commerce satisfaction/purchase behavior are significant. The non-significant relationships include the effect of trust in social media on e-commerce satisfaction $(ß=-.04, p>.05)$, the effect of trust in social commerce features on purchase behavior ( $\beta=.03, p>.05)$, and the effect of trust in consumers on purchase behavior $(\beta=.08, p>.05)$. Since previous studies have demonstrated the importance of customer reviews in e-commerce sites (See Lin, Li, and Wang [65] for a review), trust in social commerce features and trust in consumers are expected to have significant effects. However, our results show that trust in social commerce features and trust in consumers are not significant drivers of consumers’ purchase behavior in the presence of other hypothesized drivers, while trust in social media and trust in e-commerce sites are significant drivers. Meanwhile, please note that trust in social commerce features and trust in consumers are significant drivers of the other e-commerce outcome variable: e-commerce stratification. The comparison also indicates that consumers' satisfaction and purchase behavior are no longer solely based on their trust in one single object, but on their trust in multiple objects as a whole. In other words, our proposed model (trust modeled as a second-order construct consisting of multiple objects) can better explain how consume trust can be developed and affect their outcomes. As such, we can learn that consumer trust is now becoming more comprehensive as new technologies are integrated into traditional e-commerce sites. 


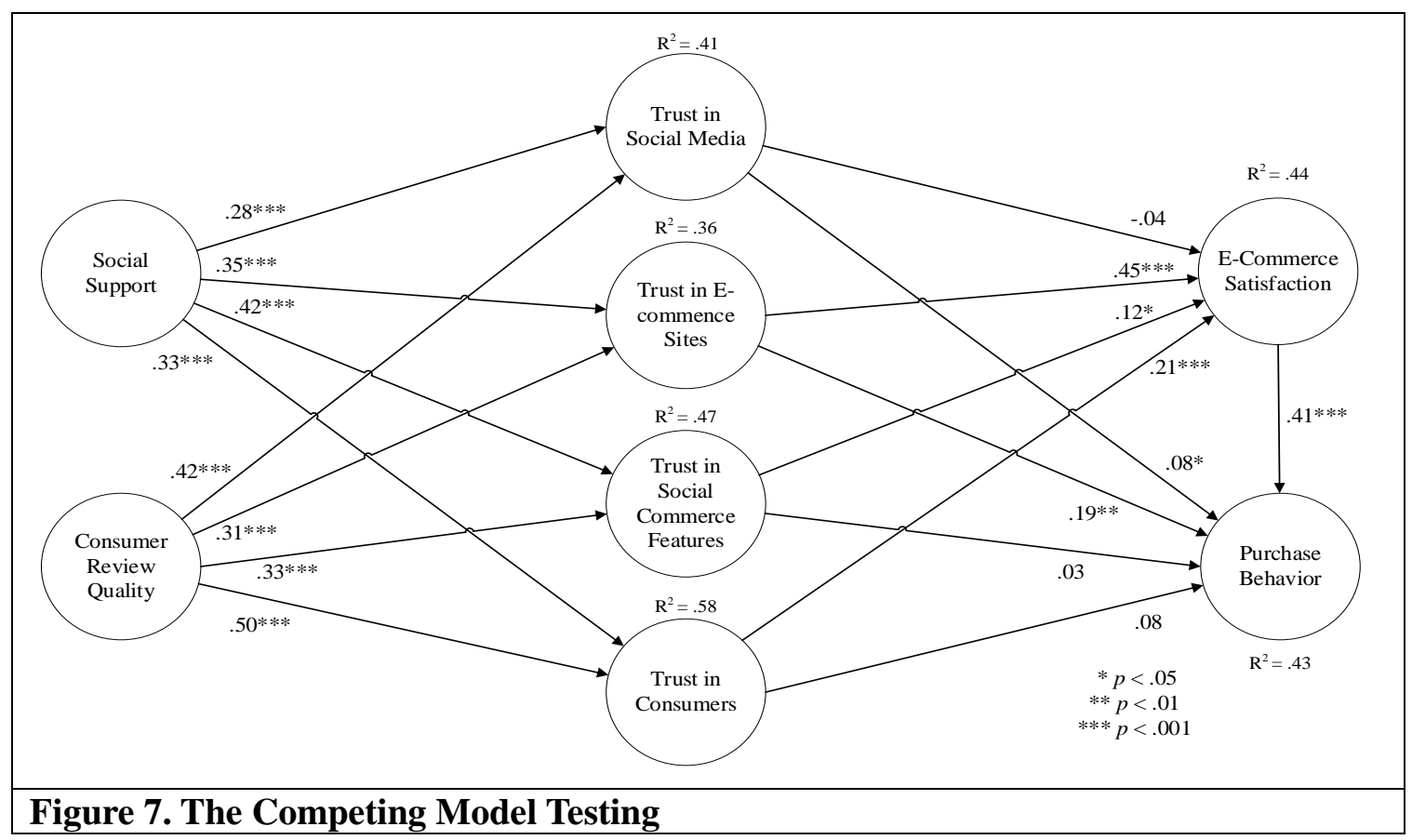

For the second criterion of model parsimony assessment, we applied classification criteria including the Akaike information criterion (AIC), the Bayes information criterion (BIC), and the consistent AIC (CAIC) [2, 25]. In these criterions, lower values represent a better fit (e.g., higher explanatory power). The results in Table 5 show that the proposed model (trust modeled as a secondorder construct) is consistently better than the competing model (trust modeled as separate first-order constructs) on all these criteria. In other words, our proposed model has better parsimonious and higher explanatory power.

Table 5. Model Parsimony Assessment

\begin{tabular}{|l|c|c|c|}
\hline & AIC & BIC & CAIC \\
\hline $\begin{array}{l}\text { The proposed model (trust modeled as } \\
\text { a second-order construct) }\end{array}$ & -19301.55 & -19061.26 & -19061.21 \\
\hline $\begin{array}{l}\text { The competing model (trust modeled } \\
\text { as separate first-order constructs) }\end{array}$ & -7632.57 & -7233.69 & -7233.60 \\
\hline
\end{tabular}

To summarize, by modeling trust as a second-order formative construct, our proposed model can better depict the effects of trust and achieve a great improvement in parsimony. Therefore, our proposed 
model is more preferred ${ }^{10}$.

\section{Discussions}

In this study, we develop a social commerce trust-based consumer decision-making model conceptualizing social commerce trust, and empirically test its effects on consumer decision making as e-commerce outcomes as well as identify its social commerce-based antecedents: social support and customer review quality. Our results validate the measures of social commerce trust from a multidimensional perspective and statistically support our conceptual model. Combining social commerce and e-commerce, this framework demonstrates that social commerce features can sufficiently build consumer social commerce trust, which leads to positive e-commerce outcomes from a consumer perspective. Therefore, our study has important implications for theory and practice.

\section{Implications for Theory}

Our study advances consumer trust theory from e-commerce to social commerce and introduces the new concept of social commerce trust combining the features of those two contexts. Social commerce is a complex environment where consumers need to interact with e-commerce sites, social media integrated with e-commerce sites, social commerce features, and other consumers. Based on socialtechnical theory, we define and conceptualize social commerce trust as a second-order construct from a multi-dimensional viewpoint (namely, the people dimension and technology dimension), which is consistent with trust theory from prior studies [56, 71]. Specifically, we identify three constructs—trust in social media, trust in e-commerce, and trust in social commerce features-for the technology dimension, and trust in consumers for the people dimension. The measures of social commerce trust are validated by our results, and all four dimensions are important and contribute to social commerce trust. Our results further show that e-commerce sites and consumers are important objects when

\footnotetext{
${ }^{10}$ On the other hand, we believe that the competing model can also add value to the literature and form a platform for future research. Our competing model can be re-tested to assess how the effects of different types of trust vary in other contexts. For example, it is possible that the effect of trust in consumers becomes strengthened relative to that of trust in e-commerce sites in the context of customer-to-customer e-commerce. We thank one reviewer for pointing this issue out.
} 
consumers form their social commerce trust. These results are consistent with previous studies in the context of e-commerce focusing on e-commerce sites (e.g., [42, 43, 57]) and consumers (e.g., [104]) separately. Our results show the important role of social media, which is also consistent with those studies conducted in the context of social media (e.g., [88]). Among few studies where different objects of trust are examined [15], trust in e-commerce sites has a larger effect than trust in consumers. This is not consistent with our study. One possible reason is that the role of consumers become more important as e-commerce sites evolve and integrate social media.

Overall, by showing that both people and technology dimension play important roles in building social commerce trust, our study confirms the social-technical theory in the context of social commerce. Among four dimensions, trust in consumers is the most important dimension in forming consumers' overall social commerce trust, followed by trust in social commerce features, trust in e-commerce sites, and trust in social media in that order. These results indicate that e-commerce sites, although still important, play a less vital role during consumers' shopping process. On the other hand, interactions among consumers are becoming more influential. These findings are valuable and pave the way for how consumer trust could be formulated by integrating new features. Specifically, as e-commerce sites include customer rating and reviews and are integrated with social media to support product information sharing, consumer trust depends not only on e-commerce sites and other consumers, but also on the reliability of customer rating and reviews and social media. Therefore, our study suggests that consumers consider a comprehensive variety of dimensions involved in their purchasing processes when developing their trust in online shopping. Social commerce trust provides further insights into consumer trust theory and could serve as a foundation for future research applying trust theory to other research contexts.

One interesting finding is that social commerce trust is positively related to e-commerce satisfaction and consumer purchasing behavior. This indicates that social commerce serves as a bridge between consumers and e-commerce sites because it enhances consumers' subjective beliefs in e-commerce and 
triggers purchasing behavior. Unlike prior studies focusing on examining the effects of social commerce on users' social commerce intention, such as sharing product knowledge and shopping experiences in social media-based social commerce $[63,106]$, our study is one of the first to examine consumer decision making in an e-commerce-based social commerce context. The research results show that social commerce plays an important role in promoting e-commerce outcomes and increasing sales. These results are also consistent with the e-commerce literature examining the effects of various types of trust [16, 74]. From this perspective, our study identifies a potential emerging research stream in a specific social commerce context where e-commerce and social commerce meet.

Social support and customer review quality are identified as key antecedents of social commerce trust. Our results show that social support and customer review quality are positively related to consumers' social commerce trust. These findings advance social support theory by bringing social support literature into a social commerce context. Social support could be viewed as a key motivation for user engagement in the emerging social media and social commerce context. Prior research mainly focuses on examining its direct effects on a variety of users' perceptions of social media attributes and usage intentions/behavior in social commerce $[40,63,65,106]$. The effect of social support provides further insight into its role in driving social commerce, thus advancing our understanding of social support theory and the social commerce phenomenon. Information quality is an important factor for successful e-commerce [23]. In the context of social commerce, information comes from other consumers. Therefore, we argue that customer review quality is another antecedent of social commerce trust. Our results are consistent with those of previous studies [29, 101] and further our understanding of how to enhance consumers' social commerce trust and increase their e-commerce satisfaction. In addition, these results further clarify the mechanisms by which social commerce trust leads to ecommerce outcomes.

Lastly, our work advances the social-technical theory to a new research context - that is, social commerce. It indicates how technological advances change the technical sub-system and social sub- 
system and how the joint interactions of the two systems affect users' behavior and outcomes. In particular, given that social sub-system has gained more attentions than the technical sub-system in social commerce (e.g., [63, 74]), our research results can shed lights on balancing the two sub-systems and enhancing their joint effects. Therefore, our work can provide some initial insights into how future research may incorporate the social-technical theory to study the impact of relatively new technology in different contexts. For example, it may be interesting to further elaborate specific variables for each sub-system and examine their impacts on consumer behaviors in the context of social commerce. For another example, the social-technical theory could be applied to other research contexts that consist of both technology and people-related issues, such as health-related information exchange on social media [102] and IT adoption [64]. In general, our work is likely to opens research avenues that socialtechnical theory can play a significant role in driving innovation and positive outcomes.

\section{Implications for Practice}

Given that our framework demonstrates business outcomes from the application of social commerce, it provides e-vendors with an enhanced understanding of the implementation of social commerce and its effects on consumer purchasing behavior. Social commerce trust is very important in driving ecommerce outcomes, and e-vendors should make efforts to manage consumer social commerce trust by implementing the relevant social commerce features on their e-commerce sites. As a multidimensional construct, consumers' social commerce trust could be formulated via a comprehensive process consisting of both technical and social features. E-vendors should balance those two features to sufficiently build consumer trust and increase sales.

Further, our results show that the weights from different dimensions of trust are not consistent. Specifically, the weights from trust in consumers and trust in social commerce features are higher than those from trust in e-commerce sites and trust in social media. These results indicate that when all four dimensions of trust are acceptable, e-vendors may want to focus more on trust in consumers and trust in social commerce features. In other words, as the platforms of e-commerce sites and social media 
mature, consumers may pay more attention to social interactions with other consumers and feel less concerned about the platforms of e-commerce and social media [98].

Lastly, our research results highlight two social commerce-based factors that may guide the successful application of social commerce. Specifically, we identify social support and customer review quality as the key determinants of consumers' social commerce trust. Our results support their effects in predicting social commerce trust. Taking advantage of these findings, e-venders may manage consumers' social commerce trust by creating an effective environment where consumers are willing to exchange social support and share high-quality customer reviews. For social support, e-commerce sites should monitor the traffic on their sites with moderators. Whenever consumers need help, these moderators can provide timely support. E-commerce sites can also recognize those who often help other consumers and provide bonuses to them. To improve the quality of customer reviews, ecommerce sites might periodically recognize the best reviews and consumer posts, and distribute gift cards or other bonuses through random draws. E-commerce sites could also let consumers vote highquality reviews themselves. Based upon these high-quality reviews, e-commerce sites can conduct analyses and understand what type of content make reviews helpful. The results can then also be shared with consumers to help them generate higher quality reviews.

\section{Limitations and Opportunities for Future Studies}

Our study has several limitations. First, we only collected self-reported purchasing behavior from consumers. Future studies are needed to collect data on real consumer purchasing behaviors and examine if the relationship still holds. Second, we only collected data from US consumers. Future studies are needed to test and extend our model with consumers from different cultural backgrounds. Third, the first criterion of our data collection requires participants to make one purchase on average per month. The reason is that if participants rarely shop on e-commerce sites, they may not have reasonable perceptions of trust and other related constructs in our study. We admit that this can be 
a limitation and our results may not be applied to all consumers. Forth, the second criterion of our data collection requires participants to often visit social media. Otherwise, they may not have reasonable perceptions of trust in social media. This again can be a limitation of our study.

Our study deals with consumers' overall purchase behaviors and does not focus on specific types of products. While this approach can increase the generalizability of our study, it does not allow us to include product-related control variables. This can be another limitation, and future studies can be conducted by focusing on specific types of products with product-related control variables.

Future studies can extend our study in several ways. First, they can test other antecedents of social commerce trust through other theoretical lenses. Second, moderators (e.g., contextual factors), and how they moderate the relationship between social commerce trust and e-commerce outcomes, can be assessed. Third, longitudinal studies can be conducted to assess if social commerce trust can indeed result in positive e-commerce outcomes. Forth, future studies could also examine other outcomes of social commerce trust, such as site loyalty, information contributing [100], customer engagement behaviors [85] and value co-creation.

\section{Conclusions}

E-commerce sites have been increasingly integrated with social media, which results in a new environment called social commerce. Practitioners are thus interested in how to promote consumer satisfaction and purchasing in such a new context. In this study, we conceptualize social commerce trust and examine its effects on e-commerce outcomes. Results from an online survey of US Amazon consumers provide strong support for our model. The new conceptualization of social commerce trust can further our understanding of trust in social commerce and build a foundation for future social commerce research. Future studies are needed to examine additional antecedents to support social commerce trust. 


\section{Reference}

1. Agag, G., and El-Masry, A.A. Understanding consumer intention to participate in online travel community and effects on consumer intention to purchase travel online and WOM: An integration of innovation diffusion theory and TAM with trust. Computers in Human Behavior, 60 (2016), 97-111.

2. Akaike, H. A new look at the statistical model identification. IEEE Transactions on Automatic Control, 19, 6 (1974), 716-723.

3. Awad, N.F., and Ragowsky, A. Establishing trust in electronic commerce through online word of mouth: An examination across genders. Journal of Management Information Systems, 24, 4 (2008), 101-121.

4. $\quad$ Ba, S.; Whinston, A.B.; and Zhang, H. Building trust in online auction markets through an economic incentive mechanism. Decision Support Systems, 35, 3 (2003), 273-286.

5. $\quad$ Belanche, D.; Casaló, L.V.; Flavián, C.; and Schepers, J. Trust transfer in the continued usage of public e-services. Information \& Management, 51, 6 (2014), 627-640.

6. Bhattacherjee, A. Individual trust in online firms: Scale development and initial test. Journal of Management Information Systems, 19, 1 (2002), 211-241.

7. Bock, G.-W.; Lee, J.; Kuan, H.-H.; and Kim, J.-H. The progression of online trust in the multichannel retailer context and the role of product uncertainty. Decision Support Systems, 53, 1 (2012), 97-107.

8. Bostrom, R.P., and Heinen, J.S. MIS problems and failures: a socio-technical perspective, part II: the application of socio-technical theory. MIS Quarterly, 1, 4 (1977), 11-28.

9. Bostrom, R.P.; Gupta, S.; and Thomas, D. A meta-theory for understanding information systems within sociotechnical systems. Journal of Management Information Systems, 26, 1 (2009), 17-48.

10. Brown, T.A. Confirmatory Factor Analysis for Applied Research. New York, NY: Guilford Publications, 2014.

11. Carter, M.; Wright, R.; Thatcher, J.B.; and Klein, R. Understanding online customers' ties to merchants: the moderating influence of trust on the relationship between switching costs and e-loyalty. European Journal of Information Systems, 23, 2 (2014), 185-204.

12. Cecere, L.; Li, C.; Etlinger, S; and Tran, C. The Rise of Social Commerce: A Trail Guide for the Social Commerce Pioneer. November 2010. https://digitalwellbeing.org/documents/Altimeter_2010.pdf. (accessed March 2019).

13. Chang, M.K.; Cheung, W.; and Tang, M. Building trust online: Interactions among trust building mechanisms. Information \& Management, 50, 7 (2013), 439-445.

14. Che, T.; Peng, Z.; Lim, K.H.; and Hua, Z. Antecedents of consumers' intention to revisit an online group-buying website: A transaction cost perspective. Information \& Management, 52, 5 (2015), 588-598.

15. Chen, J., and Shen, X.-L. Consumers' decisions in social commerce context: An empirical investigation. Decision Support Systems. 79 (2015), 55-64.

16. Chen, J.; Zhang, C.; and Xu, Y. The role of mutual trust in building members' loyalty to a C2C platform provider. International Journal of Electronic Commerce, 14, 1 (2009), 147-171.

17. Chen, X.; Huang, Q.; Davison, R.M.; and Hua, Z. What drives trust transfer? The moderating roles of seller-specific and general institutional mechanisms. International Journal of Electronic Commerce, 20, 2 (2015), 261-289.

18. Chin, W.W. Commentary: Issues and opinion on structural equation modeling. MIS Quarterly, 22, 1(1998): vii-xvi. 
19. Chiu, C.-M.; Hsu, M.-H.; Lai, H.; and Chang, C.-M. Re-examining the influence of trust on online repeat purchase intention: The moderating role of habit and its antecedents. Decision Support Systems, 53, 4 (2012), 835-845.

20. Cobb, S. Social support as a moderator of life stress. Psychosomatic Medicine, 38, 5 (1976), 300-314.

21. Delgado-Ballester, E., and HernáNdez-Espallardo, M. Effect of brand associations on consumer reactions to unknown on-line brands. International Journal of Electronic Commerce, 12, 3 (2008), 81-113.

22. Delone, W.H., and McLean, E.R. The DeLone and McLean model of information systems success: a ten-year update. Journal of Management Information Systems, 19, 4 (2003), 9-30.

23. Delone, W.H., and Mclean, E.R. Measuring e-commerce success: Applying the DeLone \& McLean information systems success model. International Journal of Electronic Commerce, 9, 1 (2004), 31-47.

24. Deng, X., and $\mathrm{Xu}, \mathrm{Y}$. Consumers' Responses to Corporate Social Responsibility Initiatives: The Mediating Role of Consumer-Company Identification. Journal of Business Ethics, 142, 3 (2017), 515-526.

25. Diamantopoulos, A., and Siguaw, J.A. Introducing LISREL: A Guide for the Uninitiated. Thousand Oaks, CA: Sage, 2013.

26. Doney, P.M., and Cannon, J.P. Trust in buyer-seller relationships. Journal of Marketing, 61 (1997), 35-51.

27. Dunne, C. Amazon Has 1,029,528 New Sellers This Year (Plus Other Stats). https://www.feedbackexpress.com/amazon-1029528-new-sellers-year-plus-stats. (accessed Novermber 2018).

28. Fang, Y.; Qureshi, I.; Sun, H.; McCole, P.; Ramsey, E.; and Lim, K.H. Trust, Satisfaction, and Online Repurchase Intention: The Moderating Role of Perceived Effectiveness of ECommerce Institutional Mechanisms. MIS Quarterly, 38, 2 (2014), 407-427.

29. Forsgren, N.; Durcikova, A.; Clay, P.F.; and Wang, X. The integrated user satisfaction model: Assessing information quality and system quality as second-order constructs in system administration. Communications of the Association for Information Systems, 38 (2016), 803839.

30. Gefen, D. Reflections on the dimensions of trust and trustworthiness among online consumers. The DATABASE for Advances in Information Systems, 33, 3 (2002), 38-53.

31. Gefen, D., and Straub, D. A practical guide to factorial validity using PLS-Graph: Tutorial and annotated example. Communications of the Association for Information Systems, 16, 1 (2005), 91-109.

32. Gefen, D.; Karahanna, E.; and Straub, D.W. Trust and TAM in online shopping: An integrated model. MIS Quarterly, 27, 1 (2003), 51-90.

33. Geisser, S. The predictive sample reuse method with applications. Journal of the American Statistical Association, 70, 350 (1975), 320-328.

34. GlobalWebIndex. GlobalWebIndex's biannual report on the latest trends in online commerce. https://www.globalwebindex.com/reports/commerce (accessed Novermber 2018).

35. Goh, K.-Y.; Heng, C.-S.; and Lin, Z. Social media brand community and consumer behavior: Quantifying the relative impact of user-and marketer-generated content. Information Systems Research, 24, 1 (2013), 88-107.

36. Gummerus, J.; Liljander, V.; Pura, M.; and Van Riel, A. Customer loyalty to content-based web sites: the case of an online health-care service. Journal of Services Marketing, 18, 3 (2004), 175-186.

37. Hair Jr, J.F., and Hult, G.T.M. A Primer on Partial Least Squares Structural Equation Modeling (PLS-SEM). Los Angeles, CA: Sage, 2016. 
38. Hajli, M.N. The role of social support on relationship quality and social commerce. Technological Forecasting and Social Change, 87 (2014), 17-27.

39. Hajli, N. Social commerce constructs and consumer's intention to buy. International Journal of Information Management, 35, 2 (2015), 183-191.

40. Hajli, N., and Sims, J. Social commerce: The transfer of power from sellers to buyers. Technological Forecasting and Social Change, 94 (2015), 350-358.

41. Hajli, N.; Sims, J.; Zadeh, A.H.; and Richard, M.-O. A social commerce investigation of the role of trust in a social networking site on purchase intentions. Journal of Business Research, 71 (2017), 133-141.

42. Hajli, N.; Wang, Y.; Tajvidi, M.; and Hajli, M.S. People, Technologies, and Organizations Interactions in a Social Commerce Era. IEEE Transactions on Engineering Management, 64, 4 (2017), 594-604.

43. Hallikainen, H., and Laukkanen, T. National culture and consumer trust in e-commerce. International Journal of Information Management, 38, 1 (2018), 97-106.

44. Hong, I.B., and Cho, H. The impact of consumer trust on attitudinal loyalty and purchase intentions in B2C e-marketplaces: Intermediary trust vs. seller trust. International Journal of Information Management, 31, 5 (2011), 469-479.

45. Hong, I.B., and Cha, H.S. The mediating role of consumer trust in an online merchant in predicting purchase intention. International Journal of Information Management, 33, 6 (2013), 927-939.

46. Hsu, M.-H.; Chang, C.-M.; and Chuang, L.-W. Understanding the determinants of online repeat purchase intention and moderating role of habit: The case of online group-buying in Taiwan. International Journal of Information Management, 35, 1 (2015), 45-56.

47. Huang, Z., and Benyoucef, M. From e-commerce to social commerce: A close look at design features. Electronic Commerce Research and Applications, 12, 4 (2013), 246-259.

48. Huang, Z., and Benyoucef, M. User preferences of social features on social commerce websites: An empirical study. Technological Forecasting and Social Change, 95 (2015), 57-72.

49. Hulland, J. Use of partial least squares (PLS) in strategic management research: A review of four recent studies. Strategic Management Journal, 20, 2 (1999), 195-204.

50. Jaiswal, A.K.; Niraj, R.; and Venugopal, P. Context-general and context-specific determinants of online satisfaction and loyalty for commerce and content sites. Journal of Interactive Marketing, 24, 3 (2010), 222-238.

51. Jones, K., and Leonard, L.N. Trust in consumer-to-consumer electronic commerce. Information \& Management, 45, 2 (2008), 88-95.

52. Kim, D.J. Self-perception-based versus transference-based trust determinants in computermediated transactions: A cross-cultural comparison study. Journal of Management Information Systems, 24, 4 (2008), 13-45.

53. Kim, D.J. A study of the multilevel and dynamic nature of trust in e-commerce from a crossstage perspective. International Journal of Electronic Commerce, 19, 1 (2014), 11-64.

54. Kim, D.J.; Ferrin, D.L.; and Rao, H.R. A trust-based consumer decision-making model in electronic commerce: The role of trust, perceived risk, and their antecedents. Decision Support Systems, 44, 2 (2008), 544-564.

55. Kim, D.J.; Ferrin, D.L.; and Rao, H.R. Trust and satisfaction, two stepping stones for successful e-commerce relationships: A longitudinal exploration. Information Systems Research, 20, 2 (2009), 237-257.

56. Kim, D.J.; Song, Y.I.; Braynov, S.B.; and Rao, H.R. A multidimensional trust formation model in B-to-C e-commerce: a conceptual framework and content analyses of academia/practitioner perspectives. Decision Support Systems, 40, 2 (2005), 143-165. 
57. Kim, D.J.; Yim, M.-S.; Sugumaran, V.; and Rao, H.R. Web assurance seal services, trust and consumers' concerns: an investigation of e-commerce transaction intentions across two nations. European Journal of Information Systems, 25, 3 (2016), 252-273.

58. Kim, G., and Koo, H. The causal relationship between risk and trust in the online marketplace: A bidirectional perspective. Computers in Human Behavior, 55 (2016), 1020-1029.

59. Kim, N., and Kim, W. Do your social media lead you to make social deal purchases? Consumer-generated social referrals for sales via social commerce. International Journal of Information Management, 39 (2018), 38-48.

60. Kim, S., and Park, H. Effects of various characteristics of social commerce (s-commerce) on consumers' trust and trust performance. International Journal of Information Management, 33, 3 (2013), 318-332.

61. Leonardi, P.M., and Vaast, E. Social media and their affordances for organizing: A review and agenda for research. Academy of Management Annals, 11, 1 (2017), 150-188.

62. Liang, T.-P., and Turban, E. Introduction to the special issue social commerce: a research framework for social commerce. International Journal of Electronic Commerce, 16, 2 (2011), 5-14.

63. Liang, T.-P.; Ho, Y.-T.; Li, Y.-W.; and Turban, E. What drives social commerce: The role of social support and relationship quality. International Journal of Electronic Commerce, 16 (2011), 69-90.

64. Lin, X.; Zhang, D.; and Li, Y. Delineating the dimensions of social support on social networking sites and their effects: a comparative model. Computers in Human Behavior, 58 (2016), 421-430.

65. Lin, X.; Li, Y.; and Wang, X. Social commerce research: Definition, research themes and the trends. International Journal of Information Management, 13, 5 (2017), 190-201.

66. Lindell, M.K., and Whitney, D.J. Accounting for common method variance in cross-sectional research designs. Journal of Applied Psychology, 86, 1 (2001), 114-121.

67. Lu, B.; Fan, W.; and Zhou, M. Social presence, trust, and social commerce purchase intention: an empirical research. Computers in Human Behavior, 56 (2016), 225-237.

68. MacKenzie, S.B. The dangers of poor construct conceptualization. Journal of the Academy of Marketing Science, 31, 3 (2003), 323-326.

69. Mayer, R.C.; Davis, J.H.; and Schoorman, F.D. An integrative model of organizational trust. Academy of Management Review, 20, 3 (1995), 709-734.

70. McKnight, D.H., and Chervany, N.L. What trust means in e-commerce customer relationships: An interdisciplinary conceptual typology. International Journal of Electronic Commerce, 6, 2 (2001), 35-59.

71. McKnight, D.H.; Choudhury, V.; and Kacmar, C. Developing and validating trust measures for e-commerce: An integrative typology. Information Systems Research, 13, 3 (2002), 334359.

72. McKnight, D.H.; Choudhury, V.; and Kacmar, C. The impact of initial consumer trust on intentions to transact with a web site: a trust building model. Journal of Strategic Information Systems, 11, 3 (2002), 297-323.

73. Molla, A., and Licker, P.S. E-commerce systems success: An attempt to extend and respecify the Delone and MacLean model of IS success. Journal of Electronic Commerce Research, 2, 4 (2001), 131-141.

74. Ng, C.S.-P. Intention to purchase on social commerce websites across cultures: A crossregional study. Information \& Management, 50, 8 (2013), 609-620.

75. Olbrich, R., and Holsing, C. Modeling consumer purchasing behavior in social shopping communities with clickstream data. International Journal of Electronic Commerce, 16, 2 (2011), 15-40. 
76. Oliveira, T.; Alhinho, M.; Rita, P.; and Dhillon, G. Modelling and testing consumer trust dimensions in e-commerce. Computers in Human Behavior, 71, (2017), 153-164.

77. Pagani, M., and Mirabello, A. The influence of personal and social-interactive engagement in social TV web sites. International Journal of Electronic Commerce, 16, 2 (2011), 41-68.

78. Palvia, P. The role of trust in e-commerce relational exchange: A unified model. Information \& Management, 46, 4 (2009), 213-220.

79. Pascual-Miguel, F.J.; Agudo-Peregrina, Á.F.; and Chaparro-Peláez, J. Influences of gender and product type on online purchasing. Journal of Business Research, 68, 7 (2015), 1550-1556.

80. Pavlou, P.A. Consumer acceptance of electronic commerce: Integrating trust and risk with the technology acceptance model. International Journal of Electronic Commerce, 7, 3 (2003), 101134.

81. Pavlou, P.A., and Fygenson, M. Understanding and predicting electronic commerce adoption: An extension of the theory of planned behavior. MIS Quarterly, 30, 1 (2006), 115-143.

82. Pavlou, P.A.; Liang, H.; and Xue, Y. Understanding and mitigating uncertainty in online exchange relationships: a principal-agent perspective. MIS Quarterly, 31, 1 (2007), 105-136.

83. Pennington, R.; Wilcox, H.D.; and Grover, V. The role of system trust in business-to-consumer transactions. Journal of Management Information Systems, 20, 3 (2003), 197-226.

84. Podsakoff, P.M.; MacKenzie, S.B.; Lee, J.-Y.; and Podsakoff, N.P. Common method biases in behavioral research: a critical review of the literature and recommended remedies. Journal of Applied Psychology, 88, 5 (2003), 879-903.

85. Prentice, C.; Wang, X.; and Lin, X. An Organic Approach to Customer Engagement and Loyalty. Journal of Computer Information Systems, (2018), 1-10.

86. $\quad$ Ringle, C.M.; Wende, S.; and Will, A. SmartPLS 2.0 (beta). Hamburg, 2005.

87. Ross, W., and LaCroix, J. Multiple meanings of trust in negotiation theory and research: A literature review and integrative model. International Journal of Conflict Management, 7, 4 (1996), 314-360.

88. Shanmugam, M.; Sun, S.; Amidi, A.; Khani, F.; and Khani, F. The applications of social commerce constructs. International Journal of Information Management, 36, 3 (2016), 425432.

89. Shi, S., and Chow, W.S. Trust development and transfer in social commerce: prior experience as moderator. Industrial Management \& Data Systems. 115, 7 (2015), 1182-1203.

90. Shin, J.I.; Chung, K.H.; Oh, J.S.; and Lee, C.W. The effect of site quality on repurchase intention in Internet shopping through mediating variables: The case of university students in South Korea. International Journal of Information Management, 33, 3 (2013), 453-463.

91. Stephen, A.T., and Toubia, O. Deriving value from social commerce networks. Journal of Marketing Research, 47, 2 (2010), 215-228.

92. Stewart, K.J. Trust transfer on the world wide web. Organization Science, 14, 1 (2003), 5-17.

93. Stone, M. Cross-validatory choice and assessment of statistical predictions. Journal of the Royal Statistical Society. Series B (Methodological), 36, 2 (1974), 111-147.

94. Suh, B., and Han, I. The impact of customer trust and perception of security control on the acceptance of electronic commerce. International Journal of Electronic Commerce, 7, 3 (2003), 135-161.

95. Taylor, S.E.; Sherman, D.K.; Kim, H.S.; Jarcho, J.; Takagi, K.; and Dunagan, M.S. Culture and social support: who seeks it and why? Journal of Personality and Social Psychology, 87, 3 (2004), 354-362.

96. Thatcher, J.B.; Carter, M.; Li, X.; and Rong, G. A Classification and Investigation of Trustees in B-to-C e-Commerce: General vs. Specific Trust. Communications of the Association for Information Systems, 32 (2013), 107-134. 
97. Wang, W.-T.; Wang, Y.-S.; and Liu, E.-R. The stickiness intention of group-buying websites: The integration of the commitment-trust theory and e-commerce success model. Information \& Management, 53, 5 (2016), 625-642.

98. Wang, X., and Li, Y. Trust, psychological need, and motivation to produce user-generated content: A self-determination perspective. Journal of Electronic Commerce Research, 15, 3 (2014), 241.

99. Wang, X.; French, B.F.; and Clay, P.F. Convergent and discriminant validity with formative measurement: A mediator perspective. Journal of Modern Applied Statistical Methods, 14, 1 (2015), 83-106.

100. Wang, X.; Lin, X.; and Spencer, M.K. Exploring the effects of extrinsic motivation on consumer behaviors in social commerce: Revealing consumers' perceptions of social commerce benefits. International Journal of Information Management, 45 (2019), 163-175.

101. Wixom, B.H., and Todd, P.A. A theoretical integration of user satisfaction and technology acceptance. Information Systems Research, 16, 1 (2005), 85-102.

102. Yan, L., and Tan, Y. Feeling blue? Go online: an empirical study of social support among patients. Information Systems Research, 25, 4 (2014), 690-709.

103. Yang, S.; Chen, Y.; and Wei, J. Understanding consumers' web-mobile shopping extension behavior: A trust transfer perspective. Journal of Computer Information Systems, 55, 2 (2015), 78-87.

104. Yoon, H.S., and Occeña, L.G. Influencing factors of trust in consumer-to-consumer electronic commerce with gender and age. International Journal of Information Management, 35, 3 (2015), 352-363.

105. Zeithaml, V.A.; Berry, L.L.; and Parasuraman, A. The behavioral consequences of service quality. Journal of Marketing, 60, 2 (1996), 31-46.

106. Zhang, H.; Lu, Y.; Gupta, S.; and Zhao, L. What motivates customers to participate in social commerce? The impact of technological environments and virtual customer experiences. Information \& Management, 51, 8 (2014), 1017-1030.

107. Zhang, K.Z., and Benyoucef, M. Consumer behavior in social commerce: A literature review. Decision Support Systems, 86 (2016), 95-108.

108. Zhang, K.Z.; Benyoucef, M.; and Zhao, S.J. Building brand loyalty in social commerce: The case of brand microblogs. Electronic Commerce Research and Applications, 15 (2016), 14-25.

109. Zhang, M.; Guo, L.; Hu, M.; and Liu, W. Influence of customer engagement with company social networks on stickiness: Mediating effect of customer value creation. International Journal of Information Management, 37, 3 (2017), 229-240.

110. Zhang, P., and Wang, C. The evolution of social commerce: an examination from the people, business, technology, and information perspective. Communication of the Association for Information Systems, 31, 5 (2012), 105-127.

111. Zhou, L.; Zhang, P.; and Zimmermann, H.-D. Social commerce research: An integrated view. Electronic Commerce Research and Applications, 12, 2 (2013), 61-68. 


\section{Appendix A: Literature Review}

\begin{tabular}{|c|c|c|c|c|c|c|}
\hline \multirow[b]{2}{*}{ Context } & \multicolumn{5}{|c|}{ Object of Trust } & \multirow[b]{2}{*}{ Sample Studies } \\
\hline & Site & People & $\begin{array}{l}\text { Social } \\
\text { Media }\end{array}$ & $\begin{array}{l}\text { Social } \\
\text { Commerce } \\
\text { Features }\end{array}$ & Other & \\
\hline $\begin{array}{l}\text { Social } \\
\text { media }\end{array}$ & $\sqrt{ }$ & & & & & $\begin{array}{l}\text { Agag and El-Masry [1], Liang, Ho, Li, and } \\
\text { Turban [63] }\end{array}$ \\
\hline $\begin{array}{l}\text { Social } \\
\text { media }\end{array}$ & $\sqrt{ }$ & $\sqrt{ }$ & & & & Chen and Shen [15] \\
\hline $\begin{array}{l}\text { Social } \\
\text { media }\end{array}$ & & & $\sqrt{ }$ & & & $\begin{array}{l}\text { Hajli [38], Hajli [39] Hajli, Sims, Zadeh, and } \\
\text { Richard [41], Shanmugam, Sun, Amidi, } \\
\text { Khani, and Khani [88] }\end{array}$ \\
\hline $\begin{array}{l}\text { Social } \\
\text { media }\end{array}$ & $\sqrt{ }$ & $\sqrt{ }$ & & & Information & Shi and Chow [89] \\
\hline $\begin{array}{l}\text { E-commerce } \\
\text { sites }\end{array}$ & $\sqrt{ }$ & & & & & $\begin{array}{l}\text { Awad and Ragowsky [3], Bock, Lee, Kuan, } \\
\text { and Kim [7], Carter, Wright, Thatcher, and } \\
\text { Klein [11], Chang, Cheung, and Tang [13], } \\
\text { Che, Peng, Lim, and Hua [14], Chiu, Hsu, } \\
\text { Lai, and Chang [19], Delgado-Ballester and } \\
\text { HernáNdez-Espallardo [21], Fang, Qureshi, } \\
\text { Sun, McCole, Ramsey, and Lim [28], Gefen, } \\
\text { Karahanna, and Straub [32], Hajli, Wang, } \\
\text { Tajvidi, and Hajli [42], Hallikainen and } \\
\text { Laukkanen [43], Hong and Cha [45], Hsu, } \\
\text { Chang, and Chuang [46], Kim [52], Kim and } \\
\text { Koo [58], Kim and Park [60], Kim, Ferrin, } \\
\text { and Rao [55], Kim, Yim, Sugumaran, and } \\
\text { Rao [57], Lu, Fan, and Zhou [67], McKnight, } \\
\text { Choudhury, and Kacmar [71], Oliveira, } \\
\text { Alhinho, Rita, and Dhillon [76], Palvia [78], } \\
\text { Pascual-Miguel, Agudo-Peregrina, and } \\
\text { Chaparro-Peláez [79], Pavlou and Fygenson } \\
\text { [81], Pennington, Wilcox, and Grover [83], } \\
\text { Shin, Chung, Oh, and Lee [90], Suh and Han } \\
\text { [94] }\end{array}$ \\
\hline $\begin{array}{l}\text { E-commerce } \\
\text { sites }\end{array}$ & $\sqrt{ }$ & & & & Sellers & $\begin{array}{l}\text { Hong and Cho [44], Wang, Wang, and Liu } \\
\text { [97] }\end{array}$ \\
\hline $\begin{array}{l}\text { E-commerce } \\
\text { sites }\end{array}$ & $\sqrt{ }$ & $\sqrt{ }$ & & & & Chen, Zhang, and Xu [16] \\
\hline $\begin{array}{l}\text { E-commerce } \\
\text { sites }\end{array}$ & $\sqrt{ }$ & & & & Sellers & Chen, Huang, Davison, and Hua [17] \\
\hline $\begin{array}{l}\text { E-commerce } \\
\text { sites }\end{array}$ & & & & & $\begin{array}{l}\text { C2C e- } \\
\text { commerce }\end{array}$ & Jones and Leonard [51] \\
\hline $\begin{array}{l}\text { E-commerce } \\
\text { sites }\end{array}$ & & $\sqrt{ }$ & & & $\begin{array}{l}\text { C2C e- } \\
\text { commerce }\end{array}$ & Yoon and Occeña [104] \\
\hline
\end{tabular}




\begin{tabular}{|l|l|l|l|l|l|}
\hline $\begin{array}{l}\text { E-commerce } \\
\text { sites }\end{array}$ & $\sqrt{ }$ & & & Internet & Kim [53] \\
\hline $\begin{array}{l}\text { E-commerce } \\
\text { sites }\end{array}$ & $\sqrt{ }$ & & $\begin{array}{c}\text { Merchant; IT } \\
\text { infrastructure; } \\
\text { Institutional } \\
\text { mechanism }\end{array}$ & Thatcher, Carter, Li, and Rong [96] \\
\hline
\end{tabular}

